\title{
More Than Mortar: Glia as Architects of Nervous System Development and Disease
}

\author{
Inês Lago-Baldaia', Vilaiwan M. Fernandes ${ }^{1 *}$ and Sarah D. Ackerman ${ }^{2 *}$ \\ ${ }^{1}$ Department of Cell and Developmental Biology, University College London, London, United Kingdom, ${ }^{2}$ Institute \\ of Neuroscience, Howard Hughes Medical Institute, University of Oregon, Eugene, OR, United States
}

Glial cells are an essential component of the nervous system of vertebrates and invertebrates. In the human brain, glia are as numerous as neurons, yet the importance of glia to nearly every aspect of nervous system development has only been expounded over the last several decades. Glia are now known to regulate neural specification, synaptogenesis, synapse function, and even broad circuit function. Given their ubiquity, it is not surprising that the contribution of glia to neuronal disease pathogenesis is a growing area of research. In this review, we will summarize the accumulated evidence of glial participation in several distinct phases of nervous system development and organization-neural specification, circuit wiring, and circuit function. Finally, we will

Edited by:

Tim Czopka,

University of Edinburgh, United Kingdom

Reviewed by:

Cody J. Smith,

University of Notre Dame,

United States

Stefanie Schirmeier,

University of Münster, Germany

${ }^{*}$ Correspondence:

Vilaiwan M. Fernandes

vilaiwan.fernandes@ucl.ac.uk

Sarah D. Ackerman

sarah.d.ackerman@gmail.com

Specialty section

This article was submitted to

Molecular Medicine

a section of the journal

Frontiers in Cell and Developmental

Biology

Received: 28 September 2020

Accepted: 17 November 2020

Published: 14 December 2020

Citation:

Lago-Baldaia I, Fernandes VM and Ackerman SD (2020) More Than Mortar: Glia as Architects of Nervous

System Development and Disease.

Front. Cell Dev. Biol. 8:611269.

doi: 10.3389/fcell.2020.611269 dysfunction in neurodevelopmental and neurodegenerative disorders.

Keywords: glia, nervous system development, neural specification, circuit wiring, circuit function, neurodevelopmental disorders, neurodegenerative disorders

\section{INTRODUCTION}

Long past the days of being relegated to nervous system "glue," today glia are acknowledged as essential players in nervous system development and function (Allen and Lyons, 2018). Given that glia-like cells are present in the most evolutionarily ancient bilateria, and share common features and functions across divergent species (Verkhratsky et al., 2019), it is unsurprising that invertebrate and vertebrate genetic model organisms have expanded our understanding of the multifaceted roles that glia play in the developing and mature nervous system (Sieger and Peri, 2013; Ackerman and Monk, 2016; Allen and Eroglu, 2017; Kremer et al., 2017; Singhvi and Shaham, 2019; Yildirim et al., 2019).

Glial cell populations can be subdivided based on lineage and function, most of which are conserved from invertebrates through humans (Figures 1, 2). Dysfunction of these glial populations has been documented in various neurological disorders, including Huntington's disease, glioma, and autism (Phatnani and Maniatis, 2015; Hambardzumyan et al., 2016; Dulamea, 2017; Liddelow and Barres, 2017; Neniskyte and Gross, 2017; Hickman et al., 2018; Santosa et al., 2018), but whether glial cell impairments are causative or simply symptomatic of pathology is not yet understood. We propose that characterizing glial function under normal physiological conditions will inform our understanding of the etiology of neurological disorders, which is essential for successful therapeutic intervention. In this review, we will highlight findings from vertebrate and invertebrate systems that focus on roles of glia in nervous system development, and discuss how defects in these processes may contribute to neurodevelopmental and neurodegenerative disease. 


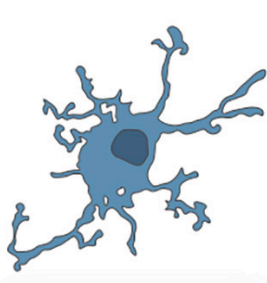

Microglia

General Immune surveillance; Cellular functions and axonal debris clearance; Extracellular matrix remodeling

C. elegans Mesoderm-derived GLR glia

Drosophila Astrocytes; Ensheathing glia; Cortex glia

Zebrafish Microglia

Rodents Microglia

Human Microglia

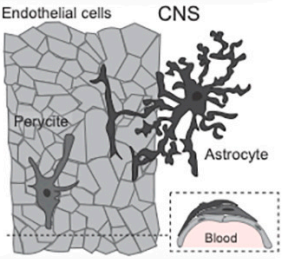

Blood brain/nerve barrier $\begin{array}{ll}\begin{array}{l}\text { General } \\ \text { functions }\end{array} & \begin{array}{l}\text { Regulated/selective interface } \\ \text { between plasma circulation } \\ \text { and nervous system }\end{array}\end{array}$

C. elegans Cephalic Sheath glia

Drosophila

Perineurial glia; Subperineurial glia

Zebrafish Perycites (CNS); Perineurial glia (PNS)

Rodents

Perycites and Astrocytes (CNS); Perineurial glia (PNS)

Human
Perycites and Astrocytes (CNS); Perineurial glia (PNS)

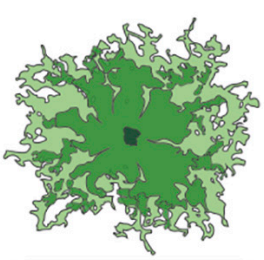

Astrocytes

Neurovascular coupling; Ion homeostasis; Neurotransmitter turnover; Synaptogenesis; Neuronal remodeling; Synapse and circuit function

Cephalic Sheath glia

Astrocytes

Astrocytes; Radial astrocytes Bergmann glia, Müller glia

Astrocytes; Bergmann glia, Müller glia

Astrocytes; Bergmann glia; Müller glia

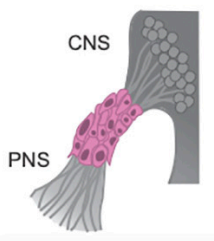

\section{Transition zone glia}

Delimitation of CNS-PNS boundary:

Not determined

Peripheral ensheathing glia; Wrapping glia

Motor exit point glia; Olfactory ensheathing glia

Boundary cap cells; Olfactory ensheathing glia

Boundary cap cells; Olfactory ensheathing glia

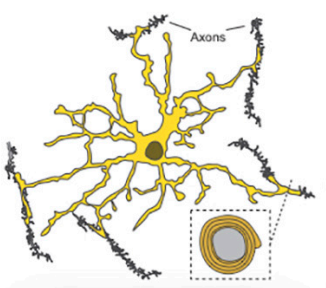

Oligodendrocytes

Axon support; Central brain nerve myelination; Neuronal conductance; Metabolic support of neurons

Cephalic Sheath glia (non-myelinating)

Neuropil ensheathing glia; Embryonic longitudinal glia (both non-myelinating)

Oligodendrocytes

Oligodendrocytes

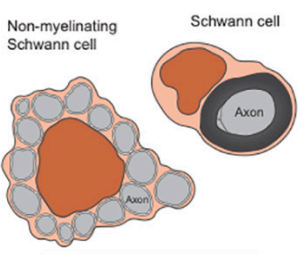

Schwann cells

Axon support; Peripheral nerve myelination or non-myelinated enwrapping

non-myelinated enwrapping: Neuronal conductance, Axonal debris clearance

All sheath glia (non-myelinating)

Peripheral ensheathing glia; Wrapping glia
(both non-myelinating)

Remak (non-myelinating) and myelinating Schwann cells

\section{Oligodendrocytes}

Remak (non-myelinating) and myelinating Schwann cells

Remak (non-myelinating) and myelinating Schwann cells

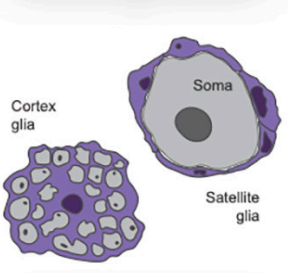

Soma-associated glia

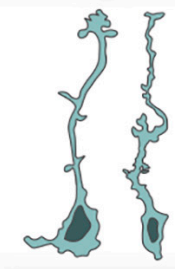

\section{Radial glia}

Metabolic/Trophic support; Cellular debris clearance; Axon regeneration

Neuronal and glial progenito cells; Radial neuronal migration

Not determined

Cephalic and Inner labia sheath glia (embryo); Amphid socket glia (larva)

Cortex glia

Not present (Neuroblasts)

Satellite glia

Radial glia

Satellite glia

Radial glia

Satellite glia

Radial glia

FIGURE 1 | Glial subtypes of the central and peripheral nervous systems. The primary vertebrate glial subtypes can be broken down into the following categories: microglia (schematized in blue), astrocytes (green), oligodendrocytes (yellow), Schwann cells (orange), blood-brain and blood-nerve barrier glia (gray), transition zone glia (pink), soma-associated glial cells (purple), and radial glia (teal). A functional description of each glial subtype is provided below each schematic, followed by a table indicating the orthologous glial cell population in the primary model organisms (C. elegans, Drosophila, zebrafish, rodent) and in human. 


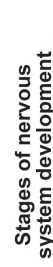

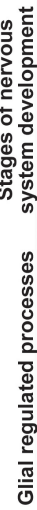

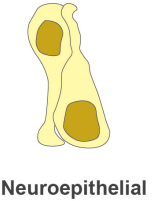 cells

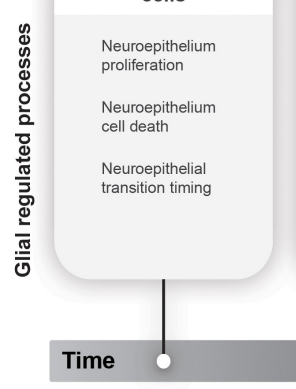 \\ Neuroepithelial transition
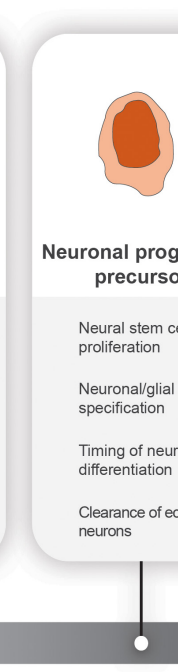 \\ Neuronal progenitorl precursor \\ Neural stem cell Neural stem cell
proliferation \\ Neuronalglial specification \\ Timing of neuronal differentiation \\ Clearance of ectopic neurons

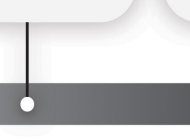 \\ Neuronal \\ specification developmental time. \\ GLIA REGULATE BRAIN SIZE AND NEURONAL NUMBERS}

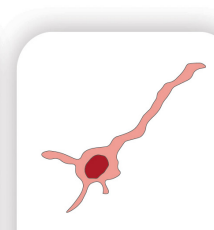

Newborn neuron

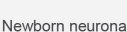

Newborn
survival

Radial neuronal

Radial neu
migration

Tangential neurona

Tangential
migration

FIGURE 2 | Glial cell functions in nervous system development. Progression from neuroepithelial cells (yellow) to functional neural circuits (purple) over

Nervous systems are highly heterogeneous structures, containing more unique cell types than any other organ. During development, neuroepithelial cells expand through symmetric mitoses before being converted into neural stem cells (NSCs). These neural stem cells (called neuroblasts in Drosophila) must divide for a stereotyped period of time. Their progeny, postmitotic neurons and glia, must then adopt distinct fates in proper numbers and stoichiometry before connecting with the appropriate partners to form functional circuits (McKay, 1989; Brody and Odenwald, 2002; Riccomagno and Kolodkin, 2015; Silbereis et al., 2016; Beattie and Hippenmeyer, 2017; Doe, 2017; Li et al., 2018). Our ability to process sensory information and perform complex tasks depends critically on the timely generation and wiring of diverse neural subtypes into functional circuits. Accordingly, altering neuronal numbers, stoichiometry, diversity, and connectivity all have profound impacts on brain function.

\section{Glial Regulation of Neuroepithelial Expansion and Transition}

In vertebrates, NSCs of the developing brain and spinal cord are called radial glia (Doetsch et al., 1999; Malatesta et al., 2000; Noctor et al., 2001; Kriegstein and Alvarez-Buylla, 2009). During development, radial glia first enter a neurogenic phase to generate neurons, and then switch to a gliogenic phase for production of oligodendrocytes and astrocytes (Malatesta and Götz, 2013; Götz et al., 2016). In contrast, the production of post-mitotic neurons and glia occurs in parallel in Drosophila (Homem and Knoblich, 2012). Accordingly, Drosophila glial cells form an important component of the NSC niche that regulates neurogenesis
(Doe, 2017). This has been well-studied within the Drosophila visual system, which arises from a specialized neuroepithelium during development called the outer proliferation center (OPC). This neuroepithelium is located at the surface of the developing optic lobe, where it generates the neurons of the medulla and lamina neuropils. The OPC proliferates and expands during the first and second larval instars before a proneural wave sweeps across the epithelium, resulting in a switch to asymmetric division for generation of neuroblasts (Doe, 2017; Holguera and Desplan, 2018). Immature cortex glia sit atop the OPC and send extrinsic cues to set the balance between neuroepithelial expansion and neuroblast transition. Cortex glia activate Notch signaling in neuroepithelial cells through the membrane-bound ligand Serrate, which maintains epithelial cell proliferation and delays proneural wave progression (Pérez-Gómez et al., 2013). Cortex glia also secrete the Epidermal Growth Factor (EGF) Spitz, which activates EGF Receptor (EGFR) signaling in the epithelium; EGFR activity inhibits Notch to promote proneural wave progression and the transition to neuroblasts (Morante et al., 2013). The relative strength of Notch and EGF signaling within the neuroepithelium governs the timing of this transition (Egger et al., 2010; Yasugi et al., 2010). What controls the balance of these two glial-derived cues is not yet understood. More recently, expression of the chloride channel CIC-a in cortex glia was also shown to promote neuroepithelial expansion, suggesting that glia-mediated ion homeostasis within the niche can temporally control the transition to neurogenesis (Plazaola-Sasieta et al., 2019).

\section{Glia and the Timing of Neural Progenitor Proliferation}

In Drosophila, glia can secrete factors to regulate neuroblast proliferation and consequently, neuronal numbers. For example, 
glial-secretion of the glycoprotein Anachronism represses neuroblast proliferation (Ebens et al., 1993), whereas surface localization of the heparan sulfate proteoglycan Dally-like (Kanai et al., 2018) or E-cadherin (Dumstrei et al., 2003) promotes neuroblast proliferation. The best characterized instance of glia regulating neuroblast proliferation is that of neuroblast reactivation following quiescence. At the end of embryogenesis, neuroblasts enter quiescence and later reactivate in response to feeding during larval life. Neuroblast re-activation requires a nutrient-dependent fat-body-derived signal (Britton and Edgar, 1998; Chell and Brand, 2010; Sousa-Nunes et al., 2011; Yuan et al., 2020). Surface and cortex glia receive this signal, and in response, secrete Insulin-like peptides to reactivate quiescent neuroblasts (Chell and Brand, 2010; Sousa-Nunes et al., 2011; Yuan et al., 2020). A similar mechanism of glial relay through Insulin Receptor signaling was described for the differentiation of lamina neural precursors in the optic lobe, which is necessary for the correct formation of the retinotopic visual system (Fernandes et al., 2017).

Macroglia (astrocytes and oligodendrocytes) are not present during vertebrate neurogenesis in the embryonic central nervous system (CNS). In contrast, microglial populations migrate from the yolk sac into CNS during early embryonic development (Sominsky et al., 2018), and are therefore present at the correct time and place to modulate neurogenesis (Aarum et al., 2003; Antony et al., 2011). Several key in vitro studies using primary murine neural progenitor cells were the first to demonstrate the ability of microglia to influence developmental neurogenesis. First, both embryonic and adult neural stem cells could migrate along gradients of microglia-conditioned medium (Aarum et al., 2003). Microglia were later found to secrete mitogenic factors that induce neural stem cell proliferation in a PI3K and Notchdependent fashion (Morgan et al., 2004), similar to Drosophila cortex glia (Pérez-Gómez et al., 2013). Furthermore, addition of microglia can prolong neurogenesis in cultured subventricular zone-derived neurospheres (Walton et al., 2006). Finally, analysis of PU.1 $1^{-/-}$mice, which disrupts microglial development, revealed a decrease in cortical progenitor proliferation in vitro (Antony et al., 2011). In vivo analysis of microglia-dependent embryonic neurogenesis is limited, yet microglia have been shown to regulate the timing of neural differentiation in the zebrafish developing retina (Huang et al., 2012). Here, knockdown of the cell surface protein Colony stimulating factor1 receptor suppressed entry of microglia into the CNS. Lack of microglia delayed the differentiation of retinal neurons and increased the number of proliferative progenitors, resulting in an immature optic lobe (Huang et al., 2012).

In mammals, both microglia and macroglia regulate adult neurogenesis (reviewed in Falk and Götz, 2017). Co-culturing astrocytes with adult NSCs derived from the hippocampus is sufficient to induce NSC proliferation in vitro (Song et al., 2002). Elegant data both in vitro and in vivo have since defined that complex extrinsic cues from astrocytes and oligodendrocyte precursor cells can bias adult NSCs toward neurogenic or gliogenic trajectories (Peretto et al., 2004; Lie et al., 2005; Barkho et al., 2006; Ferrón et al., 2011; Ashton et al., 2012; Shin et al., 2015). For example, astrocyte-derived Wnt7a instructs neurogenesis (Moreno-Estellés et al., 2012), whereas oligodendrocyte precursor-derived Wnt3a promotes generation of additional oligodendrocyte precursor cells (Ortega et al., 2013). Microglia are primarily thought to regulate hippocampal neurogenesis through pruning of supernumerary neurons that undergo apoptosis (discussed further below, Sierra et al., 2010). Interestingly, a recent report found that microglial phagocytosis induces a cell-autonomous transcriptional cascade, resulting in secretion of factors that are required for continued proliferation of residual neural stem cells. Accordingly, mouse models with disrupted microglial phagocytosis (P2Y12 $12^{-/}$and microgliaspecific knockout of MerTK/Axl) showed reduced hippocampal neurogenesis (Diaz-Aparicio et al., 2020). Together, these data show that glia influence developmental and adult neurogenesis through modulation of neural proliferation, and survival.

\section{Glial Cell Dysfunction and Diseases That Alter Brain Size}

Since neurons are postmitotic, neuroepithelial expansion and neural stem cell proliferation are key to regulating neuronal numbers, and consequently, organ size. Defects in neuroepithelial expansion, neural stem cell proliferation, as well as the timing of transitions between these states may therefore lead to developmental disorders that alter brain size (e.g., microcephaly or macrocephaly) (Jamuar and Walsh, 2015). Macrocephaly, characterized by increased head circumference, is also common in autism patients (Lainhart et al., 2006; Grandgeorge et al., 2013; Gamsiz et al., 2015). Indeed, a mammalian model of autism/macrocephaly showed over-proliferation of neural precursors caused by deregulation of mTOR/PI3K signaling (Zhang et al., 2020), which is known to instruct stem cell proliferation during development (Chell and Brand, 2010; SousaNunes et al., 2011; Yuan et al., 2020).

Given that altering the duration of radial glial proliferation can bias cell fate decisions (Pilaz et al., 2016), defects in radial glial proliferation could manifest in many different neurodevelopmental disorders. In humans, mutations in Fragile X Mental Retardation 1 (FMR1) causes Fragile X syndrome, a disease associated with severe cognitive deficits and autismlike behaviors (Salcedo-Arellano et al., 2020). In Drosophila, Fmr1/Fmrp is required in neuroblasts and non-autonomously in glia for timely neuroblast reactivation, which is dependent on insulin-like signaling (Callan et al., 2012). Interestingly, FMR1/FMRP is robustly expressed in microglia during brain development (Gholizadeh et al., 2015), and consequently, microglial numbers are reduced in FMR1/FMRP knockout mice (Lee et al., 2019). Since microglia are able to secrete Insulin to induce post-natal neural survival (Ueno et al., 2013), they may also play an important role in neuronal survival or stem cell activation in the etiology of Fragile $\mathrm{X}$ syndrome.

The regulation of neurogenesis in mammalian adult neural stem cell niches is especially relevant in the context of neurodegenerative diseases or injury, where the replacement of dead neurons is necessary for recovery (Ghosh, 2019). Adult neurogenic niches are populated by microglia and astrocytes 
which can modulate cell number and cell fate decisions (AlvarezBuylla et al., 2008; Sierra et al., 2010; Than-Trong and Bally-Cuif, 2015; Bonzano et al., 2018; Sirerol-Piquer et al., 2019; Vicidomini et al., 2020). NSC reactivation is induced by exercise as well as feeding, which involve insulin signaling fluctuations (Bjornsson et al., 2015; Licht and Keshet, 2015; Otsuki and Brand, 2020). Astrocytic as well as microglial expression of IGF1 has been linked to adult NSC proliferation (Yan et al., 2006; Ueno et al., 2013). These findings raise the possibility that Insulin-resistance associated with Alzheimer's disease (AD) could influence glialmediated NSC proliferation, and thus, regeneration (Ferreira et al., 2018). Indeed, AD models show a decrease in neuronal progenitor proliferation (Rodríguez and Verkhratsky, 2011). Additionally, levels of IGF1 receptor as well as insulin are dysregulated in AD animal models in human disease tissue, including in astrocytes (Crews et al., 1992; Connor et al., 1997; Frölich et al., 1999; Jafferali et al., 2000; Steen et al., 2005; Moloney et al., 2010; Gupta et al., 2018). Whether these changes are pathogenic is not yet clear; however, further analysis of the role of glia in regulation of Insulin/IGF1 signaling and NSC proliferation may be an important avenue of investigation to understand $\mathrm{AD}$ development and progression.

\section{DEVELOPMENTAL CELL DEATH AND NEURONAL SURVIVAL}

In addition to neuroepithelial expansion and stem cell proliferation, neuronal numbers can also be modulated by programmed cell death (PCD). PCD is essential for appropriate nervous system development. PCD eliminates excess, obsolete, or "damaged/incorrect" cells, and therefore serves as a means to adjust neuronal populations to refine circuit formation (Oppenheim, 1991; Buss et al., 2006; Miura, 2012; Yamaguchi and Miura, 2015). Different types of PCD occur during development, but the most well-studied is apoptosis, which is conserved in invertebrates and vertebrates (Kornbluth and White, 2005; Maghsoudi et al., 2012; Zakerp et al., 2015). When triggered, apoptosis induces a signaling cascade that ultimately results in activation of caspases that completely break down the proteome of the cell, priming the cell for elimination (Elmore, 2007; Singh et al., 2019). The decision to trigger PCD is controlled by a balance of cell death and cell survival signals, and glia are active participants in this regulatory process (Burek and Oppenheim, 1996; Frade and Barde, 1998; Sedel et al., 2004; Bredesen et al., 2006; Coutinho-Budd et al., 2017).

\section{Regulation of Programmed Cell Death by Glia}

One of the earliest studies to define glia-derived signals that activate neuronal death was described in the chick embryonic retina. This pioneering work demonstrated that the secreted neurotrophic factor NGF (Nerve Growth Factor) is exclusively expressed by microglia during early embryogenesis and is required to induce cell death in the early retinal neuroepithelium (Frade and Barde, 1998). NGF can promote cell survival through binding and activation of receptor tyrosine kinases (TrkA); however, here, NGF leads to cell death through neurotrophin p75 receptors (Frade and Barde, 1998). Cell death is prevalent in this epithelium in vertebrates and is essential for normal development (Vecino et al., 2004), although the exact physiological role of this high death rate is not known. It is hypothesized that PCD may be necessary to create space for the incoming axons of retinal ganglion cells forming the optic nerve at the center of the retina (Frade and Barde, 1998).

Microglia play a similarly critical role in controlling cell death within the developing motor circuit. Motoneurons are born in excess in the vertebrate spinal cord (Hamburger and Oppenheim, 1982; Pettmann and Henderson, 1998; Eisen and Melancon, 2001; Sedel et al., 2004). During late embryonic development, post-mitotic motoneurons compete for trophic factors during synaptogenesis and undergo apoptosis in order to reach a 1:1 stoichiometry of motoneuron to myotube. Selective apoptosis is triggered by activation of TNF receptor 1 on motoneurons by the pro-death factor TNF $\alpha$ (Tumor necrosis factor $\alpha$ ) secreted by microglia (Sedel et al., 2004). Interestingly, microglia utilize different pro-apoptotic pathways depending on the cellular and developmental context. Integrin $\mathrm{CD} 11 \mathrm{~b}$ and immunoreceptor DAP12 expressed in microglia similarly promote cell death of hippocampal neurons perinatally (Wakselman et al., 2008). During post-natal development, microglia trigger cell death of Purkinje cells, a cerebellum neural population, through release of superoxide ions (Marín-Teva et al., 2004). Interestingly, microglia can also shape brain development through active engulfment of viable neural precursor cells and oligodendrocyte precursor cells (Cunningham et al., 2013; Nemes-Baran et al., 2020), demonstrating that microglia-mediated engulfment can profoundly impact cell numbers within the CNS.

Glia also regulate neuronal cell numbers by actively promoting cell survival. In Drosophila, neuronal cell bodies are surrounded by cortex glia that extend processes to envelop differentiated neurons. During development, correct morphology and physiology of cortex glia is required for the survival of new-born neurons (Coutinho-Budd et al., 2017; Spéder and Brand, 2018; Plazaola-Sasieta et al., 2019; Yuan et al., 2020). Cortex glia exclusively surround neuronal cell bodies. Morphologically, cortex glia are most akin to mammalian satellite glial cells, which have also been shown to promote survival of postganglionic sympathetic neurons in the peripheral nervous system (PNS) (Enes et al., 2020). Further mechanistic and descriptive study of each of these cell types is needed before concluding the functional equivalency of cortex and satellite glia. In the CNS, microglia promote neuronal survival in vitro and in vivo (Polazzi et al., 2001; Ueno et al., 2013; Littlejohn et al., 2020). Specifically, microglial-derived IGF1 can promote survival of layer V cortical neurons during post-natal development (Ueno et al., 2013) and in new-born hippocampal neurons after injury (Littlejohn et al., 2020). The balance between apoptosis and neuronal survival during nervous system development is essential to promote maturation and homeostasis of newly formed neuronal circuits (Marín-Teva et al., 2004; Pfisterer and Khodosevich, 2017); thus, glia are key mediators of circuit development (discussed further below). 


\section{Clearance of Neuronal Debris by Glia in Development}

In addition to regulating overall cell numbers, glia modulate brain development through clearance of neural debris following apoptosis (Marín-Teva et al., 2004) and during activitydependent neuronal remodeling (Fuentes-Medel et al., 2009; Paolicelli et al., 2011; Santosa et al., 2018; Wilton et al., 2019). Since the CNS is partially isolated from blood circulation by the blood-brain barrier and is therefore inaccessible to circulating macrophages, glial cells with phagocytic capacity are responsible for clearing cellular and axonal debris in the developing and mature nervous system (Kurant, 2011; Shklyar et al., 2014; Shklover et al., 2015; Galloway et al., 2019). As the resident immune cells of the nervous system, this function is performed primarily by microglia in vertebrates (Ferrer et al., 1990; Calderó et al., 2009; Napoli and Neumann, 2009; Cunningham et al., 2013; Lyons and Talbot, 2015; Morsch et al., 2015; Prinz et al., 2019); however, other glial subtypes exhibit phagocytic activity, such as astrocytes (Chung et al., 2013; Iram et al., 2016), olfactory ensheathing cells in the olfactory system (Nazareth et al., 2015), satellite glia precursors of the developing dorsal root ganglia $(\mathrm{Wu}$ et al., 2009), Müller glia in the retina (reviewed in BejaranoEscobar et al., 2017), and Schwann cells that occupy peripheral nerves and neuromuscular junctions (Reichert et al., 1994; Lutz et al., 2017; Santosa et al., 2018). Since there is no microglia equivalent in Drosophila, other subtypes of glia take up this role (Figure 1), including cortex glia (Kurant et al., 2008; Doherty et al., 2009; McLaughlin et al., 2019), astrocytes (Tasdemir-Yilmaz and Freeman, 2014; Hilu-Dadia et al., 2018), and ensheathing glia (Doherty et al., 2009; Musashe et al., 2016; Hilu-Dadia et al., 2018). One of the best-described conserved mechanisms for phagocytosis by macroglia is through the engulfment receptor MEGF10 (Multiple EGF-like domains 10), ortholog of Draper in Drosophila, and CED-1 in C. elegans. This receptor was first shown to be required for phagocytosis by neighboring engulfing cells during C. elegans development (Zhou et al., 2001), and soon after, shown to be used for phagocytosis by glial cells in Drosophila (Freeman et al., 2003; Awasaki et al., 2006; MacDonald et al., 2006). We now know that mammalian glia require this receptor for both axonal (Chung et al., 2013) and apoptotic cellular debris clearance (Wu et al., 2009; Iram et al., 2016), nicely illustrating the conservation of glial phagocytosis at the molecular and cellular level.

\section{Ectopic Phagocytic Activity of Glia in Disease}

Glial clearance of neural debris is particularly relevant in the context of neurodegenerative diseases, such as Parkinson's and AD. Phagocytic glial cells seem to have a neuroprotective effect in clearance of toxic protein aggregates characteristic of early stages of degeneration (Yeh et al., 2016; Ho, 2019). However long-term accumulation of aggregates leads to increased microglial and astrocytic activation, and therefore excessive phagocytic activity and inflammation (Glass et al., 2010; Liddelow et al., 2017), creating a chronic toxic environment that aggravates neurodegeneration (discussed further in section "Glial
Regulation of Synapse Numbers"). Here, we will focus on glial roles in the modulation of PCD and neuronal survival during nervous system development. Considering the functions of glia in differentially promoting neuronal survival and death during development, disruption of glia-mediated neuronal apoptosis could contribute to the etiology of neurodevelopmental diseases. In fact, recent work in a zebrafish model of RNAseT2-deficient leukoencephalopathy (characterized by myelin defects that lead to motor and cognitive decline) suggest that early developmental defects in apoptotic cell phagocytosis by microglia contribute to pathology (Hamilton et al., 2020). Increases in glia-mediated neuronal apoptosis are similarly detrimental to brain function. Alexander disease is caused by mutations in the glial fibrillary acidic protein (GFAP). Disease-associated mutations result in severe astrocyte dysfunction, causing a leukoencephalopathy that is frequently accompanied by macrocephaly, seizures, and psychomotor retardation (Brenner et al., 2001; Quinlan et al., 2007). Using a Drosophila model of Alexander disease, Wang and colleagues recently showed that diseased glia non-autonomously induce neuronal cell death by releasing nitric oxide (Wang L. et al., 2015). Thus, glia non-autonomously regulate cell numbers in development, and loss of this regulation can manifest in human disease.

\section{GLIA IN NEURONAL MIGRATION AND PATHFINDING OF AXONS AND DENDRITES}

From invertebrates to vertebrates, neurons and their progenitors migrate to precise positions within the nervous system, where they will eventually extend axons to find their respective partners. The spatial and temporal precision of neuronal positioning and neurite extension is essential for the assembly of correct neural circuits and for correct nervous system organization (Buchsbaum and Cappello, 2019). Glial cells also migrate to specific positions in the nervous system after being born (Klämbt, 2009), where they act as scaffolds for neuronal migration, and modify the environment to guide neuronal migration and subsequent neurite outgrowth (Allen and Lyons, 2018; Song and Dityatev, 2018; Rigby et al., 2020).

\section{Glia and Neuronal Migration}

Two major types of neuronal migration occur during the development of the mammalian cortex. Radial migration describes the migration of new-born neurons from the ventricular zone (VZ), where they originate, to the most superficial cortex layer (marginal zone). This pattern of migration results in an inside-out organization, with early born cortical neurons in superficial layers and later-born neurons in deep layers. While excitatory neurons migrate radially, inhibitory interneurons populate the cortex by tangential migration from the ganglionic eminences to the cortex, slotting horizontally into the cortical layers (Moon and Wynshaw-Boris, 2013; Buchsbaum and Cappello, 2019). As mentioned above, radial glia are the neural progenitors of the vertebrate CNS (Doetsch et al., 1999; Noctor et al., 2001), but they also serve as scaffolds for radial 
migration. Radial glia extend processes spanning from the $\mathrm{VZ}$ to the surface of the neural tube (pial surface), and these processes are substrates for neuronal migration (Rakic, 1988; Marín and Rubenstein, 2003). Interestingly, radial glia also regulate the positioning of Cajal-Retzius cells (Kwon et al., 2011), which migrate tangentially to populate the marginal zone and are essential for the correct layering of the developing cortex (reviewed in Frotscher, 1998). Microglia, in contrast to macroglia, are also present in the CNS during migration of cortical neurons (Thion and Garel, 2017). Thus, microglia are present at the right time and place to regulate cortical migration. Indeed, embryonic depletion or ectopic activation of microglia results in mispositioning of $L h x 6+$ interneurons (tangentially migrating) to upper cortical layers during early postnatal development (Squarzoni et al., 2014), showing an important role of microglia in the organization of brain circuits.

In the peripheral nervous system, glial cells also contribute to neuronal migration. Within the olfactory system, Gonadotropinreleasing hormone $(\mathrm{GnRH})$ neurons originate from the olfactory placode. GnRH neurons then migrate along the olfactory sensory neuron axons encompassed by the olfactory ensheathing cells into the developing forebrain (Wray, 2010). In the absence of Sox10 (required for neural crest-derived glial cells), olfactory ensheathing cells do not develop and GnRH neurons fail to enter the forebrain, resulting in accumulation of $\mathrm{GnRH}$ neurons at the PNS-CNS boundary. Additionally, loss of olfactory ensheathing cells disrupts $\mathrm{GnRH}$ axon targeting, demonstrating a dual role for these glial cells in organization of the neural circuits underlying olfaction (Barraud et al., 2013).

\section{Glial Regulation of Neurite Outgrowth}

Glial cells within the PNS and CNS are essential for proper guidance of axon and dendrite outgrowth (Mason and Sretavan, 1997; Poeck et al., 2001; Hidalgo, 2003; Chotard and Salecker, 2004; Chotard et al., 2005; Learte and Hidalgo, 2007; Procko and Shaham, 2010; Avraham et al., 2020; Rigby et al., 2020). This is required for directing information flow in local circuits and is also essential for broad nervous system organization. The role of glia in axon guidance has been particularly welldefined in invertebrate species. Following initial pathfinding by pioneer axons, embryonic longitudinal glia form a scaffold that enables assembly of the longitudinal connectives in the Drosophila ventral nerve cord, analogous to the vertebrate spinal cord (Hidalgo et al., 1995; Hidalgo and Booth, 2000). This function is primarily performed by cortex glia and neuropil glia in larvae to accommodate for second waves of neurogenesis (Spindler et al., 2009). In the embryo, ablation of longitudinal glia or pioneer axons results in misrouting of secondary axons from interneurons. Consequently, longitudinal connectives fail to form due to defasciculation (Hidalgo et al., 1995; Hidalgo and Booth, 2000). Similarly, loss of Schwann cells does not impair initial outgrowth of axons in the peripheral lateral line nerve in zebrafish, but results in progressive defasciculation (Raphael et al., 2010; Perlin et al., 2011).

Beyond longitudinal growth, glia also serve as "guidepost cells" to ensure proper guidance of axons that must cross the midline in Bilateria species (reviewed in Freeman and Doherty, 2006;
Chotard and Salecker, 2007; Squarzoni et al., 2015). In the Drosophila embryo, a specialized population of glial cells, aptly named "midline glia," migrate and position themselves at the CNS midline. At the midline, they ensheath the axons that compose the longitudinal tracts and commissures, and express highly conserved guidance cues that direct axonal crossing (e.g., Netrin and Slit) (Klämbt et al., 1991; Jacobs, 2000; Lemke, 2001; Learte and Hidalgo, 2007; Stork et al., 2009; Crews, 2010; Howard et al., 2019). Vertebrates have a similar population of cells that populate the ventral midline of the developing spinal cord, floorplate cells, which also use Netrins and Slit as attractive and repellent cues to regulate crossing of commissural axons, respectively (reviewed in Chotard and Salecker, 2004; Placzek and Briscoe, 2005; Crews, 2010; Evans and Bashaw, 2010). In vertebrates, communication via commissures between the two brain hemispheres can also be regulated by glia. In zebrafish, astrocyte-like glia form glial bridges across the midline of the forebrain and secrete Slit1a/Slit2/Slit3 to guide commissural and retinal axons through the anterior and postoptic commissures (Barresi et al., 2005). Correct axon guidance across the anterior commissure also requires expression of Slit2 from astrocytes in mice (Minocha et al., 2015). Moreover, both wedge glia and microglia are required for correct guidance and fasciculation of axons through the developing corpus callosum (Shu et al., 2003; Pont-Lezica et al., 2014). In general, loss of these conserved glialderived cues results in defasciculation of commissural axons, and to a lesser extent, failed midline crossing (Hidalgo et al., 1995; Hidalgo and Booth, 2000; Shu et al., 2003; Barresi et al., 2005; Minocha et al., 2015).

Interestingly, recent work in C. elegans has defined a glial cell population that instructs the initial assembly of the central nerve ring. The cephalic sheath (CEPsh) glia, which envelops the outer surface of the nerve ring once formed, extend processes to demarcate the nerve ring prior to arrival of any axonal projections. Once there, a bundle of fewer than 10 pioneer axons enter the nerve ring, followed by a stereotyped pattern of follower axons. By taking advantage of forward genetic screening approaches, it was shown that glial-derived Netrin and Semaphorin instruct pathfinding of pioneer and follower axons into the nascent nerve ring, respectively (Yoshimura et al., 2008; Rapti et al., 2017). Thus, glia are essential directors of neurite outgrowth at local and global scales.

\section{Glial Regulation of Transition Zones}

Glial cells also guide information flow by establishing boundaries throughout the nervous system, including within the CNS and PNS to separate functional units (Wandall et al., 2005; Chotard and Salecker, 2007; Kucenas, 2015; Wu et al., 2017; Bittern et al., 2020), and at the border between the CNS and PNS. Here, we focus on the role of glia at unique borders called transition zones. Transition zones are the specialized regions in the nervous system where the CNS and PNS meet (Fontenas and Kucenas, 2017; Suter and Jaworski, 2019). Because glial cell populations traverse the CNS:PNS interface in development (Sepp et al., 2001; Kucenas et al., 2008, 2009; Clark et al., 2014; Smith et al., 2014, 2016) and following injury (Adelman and Aronson, 1972; Blakemore and Patterson, 1975; Franklin and Blakemore, 1993; 
Sims et al., 1998; Green et al., 2019), this boundary must be selectively permeable. Accordingly, there are glial cell populations that sit at transition zones and regulate exit and entry of neurite projections and in some cases, whole cells (Fontenas and Kucenas, 2017). In the zebrafish spinal cord, CNS-derived glial cells populate the motor exit point (MEP) and myelinate the dorsal-most segments of motor axons. Additionally, MEP glia act as gatekeepers to prevent ectopic exit of oligodendrocytes from the spinal cord (Smith et al., 2014; Fontenas et al., 2019). In mammals and chicks, neural crest-derived boundary cap cells occupy the dorsal root exit zone and the MEP transition zone (Niederländer and Lumsden, 1996; Golding and Cohen, 1997; Vermeren et al., 2003). Cre-mediated (Krox20+) knockout of Sox10 does not disrupt boundary cap cell formation but results in migration of oligodendrocytes and astrocytes into the periphery (Fröb et al., 2012). In addition, boundary cap cells prevent ectopic exit of motor neuron cell bodies from the CNS (Vermeren et al., 2003; Bron et al., 2007). More investigation of mammalian transition zones will uncover whether neural crest-derived MEP glia are also present, and if so, how they interface with boundary cap cells. Nonetheless, despite their distinct origins, MEP glia and boundary cap cells share functional similarities and both express Wnt-inhibitory factor 1 (Coulpier et al., 2009; Smith et al., 2014; Fontenas and Kucenas, 2018), implicating Wnt-inhibitory factor 1 as a potential key regulator of transition zone function. Drosophila also have glial cell populations that occupy transition zones in the ventral nerve cord (Sepp et al., 2000, 2001) and in the central brain (Chotard and Salecker, 2007). In the developing eye, photoreceptors in the retina differentiate and extend their axons through the optic stalk in order to project into the optic lobe, and glial cells within the retina are necessary for this PNS to CNS transition (Rangarajan et al., 1999). A similar phenomenon is observed in the mammalian olfactory system (Barraud et al., 2013), as discussed above. In sum, glia are instrumental in guiding nervous system organization.

\section{Glial Contribution to Diseases Impacting Nervous System Organization}

Glia are critical regulators of axon targeting during development (Mason and Sretavan, 1997; Hidalgo, 2003; Chotard and Salecker, 2004; Learte and Hidalgo, 2007; Procko and Shaham, 2010; Rigby et al., 2020) and during regeneration (Doherty et al., 2014; Lewis and Kucenas, 2014; Jessen and Mirsky, 2016; Purice et al., 2016; Sofroniew, 2018). Accordingly, changes to glial signaling can profoundly impact axon regrowth after injury. As this topic has been recently reviewed (Rigby et al., 2020); here, we will focus on how defective glial signaling during neuronal migration contributes to human disease. Neural migration disorders (NMDs) are characterized by defects in cortical neuron migration that produce a spectrum of phenotypes including intellectual disability, epilepsy, developmental delay, and motor impairment (Buchsbaum and Cappello, 2019). The classic NMD is Lissencephaly type I, or "smooth brain," characterized by the lack of folds (gyri) on the cerebral surface and an inverted organization of the cortical layers (Moon and Wynshaw-Boris, 2013). Because cerebral gyri are not present in murine models, recent efforts to understand the etiology of NMDs have expanded beyond the mouse to alternative model systems such as nonhuman primates, ferrets, and human cerebral organoids derived from patient tissue (Wynshaw-Boris et al., 2010; Bershteyn et al., 2017; Wang, 2018; Pinson et al., 2019). These works indicate that defects in radial glia proliferation strongly contribute to reduced brain size in lissencephaly patients (Gambello et al., 2003; Pramparo et al., 2010; Wynshaw-Boris et al., 2010; Bershteyn et al., 2017); however, defects in the radial glial scaffold also contribute to lissencephaly (Caviness, 1982; Trommsdorff et al., 1999; Dulabon et al., 2000; Li et al., 2008). Mutations in REELIN, which encodes a glycoprotein, cause an autosomal recessive form of lissencephaly. Reeler mice (mutant for Reelin) exhibit over migration of neurons on radial glial processes and inverted layering of the mammalian cortex (Caviness, 1982; Trommsdorff et al., 1999; Dulabon et al., 2000). Similar to the neurons they support, astrocytes exhibit layer specific expression profiles in the cortex, which is also inverted in Reeler mice (Bayraktar et al., 2020). Astrocytes are the primary synapse-associated glial cell type and are essential for maintenance of synapse health and function (see below in section "Glial Regulation of Circuit Function"). Because astrocytes represent a heterogeneous population of cells with brain region and circuit level specificity (Bayraktar et al., 2014, 2020; Molofsky et al., 2014; John Lin et al., 2017), disorganization of astrocytes could contribute to the development of seizures in lissencephalic patients.

Finally, as discussed above, microglia arrive in the CNS concurrent with neurogenesis. Microglia have been shown to regulate tangential migration (Squarzoni et al., 2014). Although lissencephaly is primarily thought to originate from defects in radial migration, defects in tangential migration are also apparent in mouse models and human patients of Lissencephaly type I (McManus et al., 2004; Pancoast et al., 2005; Kappeler et al., 2006, 2007; Friocourt et al., 2007; Marcorelles et al., 2010). Therefore, this glial subtype is of special interest in the study of diseases with early migratory defects, including cortical malformations and other neurodevelopmental diseases with targeting defects (Squarzoni et al., 2015).

\section{GLIAL REGULATION OF SYNAPSE NUMBERS}

Following initial waves of axonal and dendrite growth, developing neurons enter a phase of rapid synaptogenesis. Glia shape overall synapse numbers within the nervous system through three primary means: (1) regulation of synapse development, (2) selective pruning of supernumerary connections, and (3) continued synapse maintenance (discussed in section "Glial Regulation of Circuit Function").

\section{Glial Regulation of Synaptogenesis}

The first evidence that glia instruct synaptic development stemmed from studies of cultured retinal ganglion cells (RGCs) (Pfrieger and Barres, 1997; Ullian et al., 2001). In these pioneering works, RGCs cultured in isolation exhibited an intrinsic ability to form a limited number of synapses, which was significantly 
enhanced when grown in astrocyte-conditioned medium (Ullian et al., 2001). More recently, astrocyte-like CEPsh neuropil glia in C. elegans (Colón-Ramos et al., 2007; Shao et al., 2013) and Drosophila astrocytes (Muthukumar et al., 2014) were similarly shown to instruct synaptogenesis. Indeed, TEM analysis revealed that ablation of Drosophila astrocytes results in a $30-50 \%$ reduction in global synapse numbers in young adult flies, depending on brain region (Muthukumar et al., 2014). In the last decade, a series of astrocyte-secreted molecules (Hevin, Thrombospondins, Glypicans, Cholesterol, and more) were identified as essential for development of structural and functional synapses in mammals and invertebrates (Allen and Eroglu, 2017). As this subject has been extensively reviewed (Chung et al., 2015; Allen and Eroglu, 2017; Farhy-Tselnicker and Allen, 2018), we will instead focus on the role of additional glial cell types in synaptogenesis.

As aforementioned, microglia are known to regulate both neurogenesis and axon targeting (Pont-Lezica et al., 2014; Ueno and Yamashita, 2014). Microglia represent the resident immune cells of the brain and are well known for their roles in synapse engulfment (see more in Synaptic pruning). Interestingly, depletion of microglia during early postnatal development, a period of rapid synaptogenesis, results in a significant reduction in spine density on Layer $2 / 3$ pyramidal neurons in mouse (Miyamoto et al., 2016). Further, live imaging demonstrated that microglial-dendritic contact was sufficient to induce spine formation (Miyamoto et al., 2016). These findings suggest that microglia also promote synapse development. Accordingly, microglia have been shown to regulate learningdependent synapse formation in the adult brain. Motor skill learning stimulates formation of dendritic spines within the motor cortex to facilitate improvement of motor performance (Yang et al., 2009; Liston et al., 2013). When microglia are depleted in postnatal mice (P19-P30), learning induced spine formation on layer $\mathrm{V}$ pyramidal neurons is impaired. Microglia-specific deletion of Brain-derived neurotrophic factor (BDNF) recapitulates this phenotype, suggesting that microglial BDNF drives learning-induced post-synaptic dendritic spines within the motor cortex (Parkhurst et al., 2013), but whether BDNF regulates synapse development more broadly was not assessed. Furthermore, a recent report found that environmental enrichment induces robust expression of IL-33 in a subset of hippocampal neurons, which stimulates microglia-dependent spine formation. Accordingly, conditional knockout (cKO) of IL-33 from neurons in the dentate gyrus and CA1 regions, or $\mathrm{cKO}$ of the obligate co-receptor Il1rl1 (Interleukin 1 receptor like 1) from microglia, suppressed experience-dependent spine formation (Nguyen et al., 2020). Excitingly, this study found that IL-33 expression stimulates microglia-dependent engulfment of Aggrecan (Nguyen et al., 2020), a chondroitin sulfate proteoglycan that forms part of the perineuronal nets that restrict neuronal plasticity (Rowlands et al., 2018). Expression of chondroitin sulfate proteoglycans suppresses activity-dependent neural circuit remodeling during early developmental windows called critical periods (Takesian and Hensch, 2013; Rowlands et al., 2018). It will be important to determine whether microglia also promote synapse formation during early phases of development by maintaining the extracellular matrix in an environment that is permissive to synaptogenesis.

Outside of the CNS, peripheral glia are also active participants in synaptogenesis at the neuromuscular junction (NMJ). In Drosophila, NMJ glia secrete the TGF- $\beta$ ligand Maverick in concert with muscle-derived TGF- $\beta$ ligands (Glass bottom boat), which activate TGF- $\beta$ receptors on motor axons to stimulate synaptic growth (Fuentes-Medel et al., 2012). Similarly, terminal Schwann cells (tSCs) at the vertebrate NMJ are necessary for expansion of motor endplates during development (Love and Thompson, 1998; Herrera et al., 2000; Darabid et al., 2014; Santosa et al., 2018), and stimulate reinnervation and synapse development following injury (Kang et al., 2003, 2019; Darabid et al., 2014; Santosa et al., 2018; Jablonka-Shariff et al., 2020). For example, extending the time to reinnervation following more severe cut injury of the nerve innervating the sternomastoid or soleus muscle in young adult mice (2-4 months post-natal) results in migration of tSCs away from the NMJ. Because motor axons depend on $\mathrm{tSC}$ guidance to the appropriate targets during regrowth, reinnervation to NMJs was misrouted and significantly delayed where tSCs were absent (Kang et al., 2014). Although the molecular mechanisms by which tSCs promote synaptogenesis following injury are limited, a recent report found $\mathrm{tSCs}$ lacking expression of the adhesion G proteincoupled receptor Gpr126/Adgrg6 fail to extend processes to guide reinnervation following crush injury of the sternomastoid muscle (Jablonka-Shariff et al., 2020). As 35\% of the drug targets on the market currently target $\mathrm{G}$ protein-coupled receptors (Sriram and Insel, 2018), this study implicates Gpr126 (Diamantopoulou et al., 2019) as a potential therapeutic target to promote axon regrowth and synapse development following human peripheral nerve injuries.

\section{Glia-Mediated Synaptic Pruning}

During development, synapses are often generated in excess of what is necessary to achieve functional neural circuits. Accordingly, circuits undergo waves of activity-dependent circuit refinement to prune away weak or redundant synapses, followed by strengthening and maintenance of surviving synapses (Riccomagno and Kolodkin, 2015; Jung et al., 2019). As noted previously (see section on "Developmental Cell Death and Neuronal Survival"), one major pruning pathway used by both invertebrate and vertebrate glia is the CED-1/Draper/Megf10 pathway (Zhou et al., 2001; Freeman et al., 2003; Awasaki et al., 2006; MacDonald et al., 2006; Tasdemir-Yilmaz and Freeman, 2014; Chung et al., 2015). Loss of this pathway from mammalian astrocytes and microglia impairs activity-dependent pruning of excess RGC synapses in the developing visual system (Chung et al., 2013). Similarly, Drosophila NMJ glia use Draper to phagocytose excess synaptic boutons on motor axons during NMJ development (Fuentes-Medel et al., 2009).

Although astrocytes contribute to synaptic pruning and remodeling (Chung et al., 2013; Hill et al., 2019), the primary phagocytic cells within the vertebrate CNS are microglia (Paolicelli et al., 2011; Wilton et al., 2019). As immune cells, microglia primarily respond to immune cues (e.g., cytokines) to guide their behaviors (Werneburg et al., 2017). The best 
described signaling axis that drives microglial-dependent synaptic pruning is the complement pathway (Hammond et al., 2018). This pathway has been extensively studied in both developmental (Stevens et al., 2007; Schafer et al., 2012; Filipello et al., 2018) and pathological conditions (Shi et al., 2015; Hong et al., 2016; Schafer et al., 2016; Vasek et al., 2016; Werneburg et al., 2020). In brief, during early postnatal development, synapses that are destined for elimination secrete the complement components $\mathrm{C} 1 \mathrm{q}$ and $\mathrm{C} 3$ as "eat me" signals that bind to the fractalkine receptor CX3CR1 on microglial membranes to trigger engulfment of the tagged synapse (Hammond et al., 2018). Microglia also receive "don't eat me" signals (e.g., CD47) to prevent ectopic synapse pruning (Lehrman et al., 2018). Interestingly, TGF$\beta$ signaling from astrocytes can stimulate $\mathrm{C} 1 \mathrm{q}$ expression in RGCs to potentiate microglial engulfment (Bialas and Stevens, 2013). Furthermore, astrocyte-derived IL-33 can bind to IL1RL1 on microglia to stimulate engulfment of excitatory glutamatergic synapses in the thalamus, and to instruct engulfment of both excitatory and inhibitory inputs onto $\alpha$ motor neurons in the spinal cord (Vainchtein et al., 2018). These studies suggest that astrocytes can greatly influence circuit refinement not only through direct synapse engulfment (Chung et al., 2013), but by directing microgliadependent pruning (Bialas and Stevens, 2013; Vainchtein et al., 2018). Although a number of neurons, microglia, and astrocyte-derived proteins have been implicated in microglial dependent pruning, how synapses are physically tagged for removal remained elusive until recently. Phosphatidylserine is a phospholipid within cell membranes that is usually localized to the inner leaflet of the plasma membrane but can be externalized to mark cells for apoptosis (Segawa and Nagata, 2015). A new study found that exposed phosphatidylserine within pre-synaptic membranes on hippocampal neurons binds to $\mathrm{Clq}$ and serves as an "eat me" signal, which in turn promotes microglial engulfment through the phagocytic receptor TREM2 (Filipello et al., 2018; Scott-Hewitt et al., 2020). Interestingly, a recent study found that TWEAK-expressing microglia drive synapse elimination in the developing visual system independent of their role in phagocytosis (Cheadle et al., 2020). Thus, glia instruct synapse numbers by promoting both developmental and activity-dependent synaptogenesis, followed by pruning (phagocytic and non-phagocytic) of excess synapses to promote circuit refinement.

\section{Glia-Mediated Changes to Synapse Stability in Disease}

Defects in a number of the aforementioned signaling pathways have been linked to both neurodevelopmental and neurodegenerative disorders (Hong et al., 2016; Vasek et al., 2016; Allen and Eroglu, 2017; Werneburg et al., 2020). Misexpression of astrocyte-derived synaptogenesis genes (e.g., Glypicans 4 and 6, Hevin, Thrombospondin 1) is evident in several autism spectrum disorders, suggesting that astrocyte dysfunction may strongly influence developmental circuit defects in humans (Allen and Eroglu, 2017). Additionally, mutant astrocytes (Lioy et al., 2011) and microglia (Schafer et al., 2016) both contribute to circuit dysfunction in a mouse model of Rett's syndrome, a neurodevelopmental disorder characterized by cognitive and motor deficits. Finally, ectopic expression of synapse pruning pathways is evident in animal and human models of neurodegeneration. Complementdriven phagocytosis of synapses by microglia is present in preclinical mouse models of multiple sclerosis (Werneburg et al., 2020), Huntington's disease (Hong et al., 2016), and prior to viral-induced memory impairment (Vasek et al., 2016). Furthermore, allelic variations of complement protein C4 are linked to increased susceptibility to schizophrenia in humans (Sekar et al., 2016; Kamitaki et al., 2020). These data implicate ectopic microglial pruning as a common underlying factor that contributes to, and may even instigate, circuit dysfunction in neurological disorders (Werneburg et al., 2017; Hammond et al., 2018).

\section{GLIAL REGULATION OF SYNAPTIC MAINTENANCE AND BASIC SYNAPTIC FUNCTION}

\section{Ion Buffering by Glia}

Following synapse establishment and refinement, perisynaptic glia ensure a permissive local environment that is absolutely essential for regulating synapse health, maintenance, and function. Proper synaptic transmission is dependent on efficient depolarization and repolarization of neuronal membranes in response to stimuli. This is achieved through tight regulation of the ionic milieu surrounding synapses $\left(\mathrm{Na}^{+}, \mathrm{K}^{+}\right.$, and $\mathrm{Cl}^{-}$), which is highly dependent on glia (Featherstone, 2011; Leiserson and Keshishian, 2011; Khakh and Sofroniew, 2015; Olsen et al., 2015; Parinejad et al., 2016). Within CNS gray matter, astrocytes are the predominant glial cell population that maintains ion homeostasis around synapses (Olsen et al., 2015; Ohno, 2018). Astrocytes express a myriad of ion channels and transporters (Olsen et al., 2006, 2015; Seifert et al., 2009, 2018; Zhang et al., 2014), but are best known for their role in potassium buffering via Kir4.1 (Kucheryavykh et al., 2007; Olsen et al., 2015). Kir4.1 is a glia-specific, inwardly rectifying $\mathrm{K}^{+}$channel that facilitates perisynaptic $\mathrm{K}^{+}$homeostasis, but also contributes to astrocyte glutamate uptake and overall astrocyte health (Dibaj et al., 2007; Djukic et al., 2007). Accordingly, astrocyte-specific knockout of Kir4.1 in mice disrupts astrocyte morphogenesis, significantly impairs $\mathrm{K}^{+}$and glutamate uptake, and results in a decrease in spontaneous network activity in the CA1 stratum radiatum (Djukic et al., 2007). In CNS white matter, astrocytic processes are only able to contact neurons at the nodes of Ranvier (Wang et al., 1993; Rash et al., 2016; Larson et al., 2018), necessitating additional glial populations for efficient $\mathrm{K}^{+}$ buffering. Both oligodendrocyte progenitor cells and myelinating oligodendrocytes strongly express Kir4.1 (Kalsi et al., 2004; Zhang et al., 2014), and contribute to clearance of $\mathrm{K}+$ from 
heavily myelinated regions of the brain that are inaccessible to astrocytic processes (Larson et al., 2018). Together, astrocytes and oligodendrocytes mediate ion homeostasis across gray and white matter regions of the vertebrate CNS, respectively, which is essential to both synaptic and circuit level function (discussed below in section "Glial Contribute to Circuit Function”).

Peripheral glia buffer extracellular ion concentrations to promote long-term synaptic and axonal health. In C. elegans, the $\mathrm{K}^{+} / \mathrm{Cl}^{-}$cation-chloride cotransporter $\mathrm{KCC}-3$ is strongly localized to membranes of the amphid sheath (AMsh) glia that support neuron receptive endings on thermosensing AFD neurons. Mutations in $k c c-3$ result in progressive retraction of neuron receptive endings (Singhvi et al., 2016). Furthermore, $k c c-$ 3 mutants fail to elicit sustained temperature-induced activation of AFD neurons, likely as a result of depleted extracellular $\mathrm{K}^{+}$ (Yoshida et al., 2016). During mouse cochlear development, activation of the purinergic autoreceptor P2RY1 on glialike inner supporting cells triggers release of $\mathrm{Cl}^{-}$through TMEM16A Ca2 ${ }^{+}$-activated $\mathrm{Cl}^{-}$channels and subsequent release of $\mathrm{K}^{+}$ions to maintain charge. This series of ion exchanges causes spontaneous depolarization of inner hair cells to initiate maturation of auditory neurons prior to the onset of hearing (Wang H. C. et al., 2015; Babola et al., 2020). Thus, glia-mediated ion buffering is essential during critical periods of circuit development and is necessary for long term synaptic health.

\section{Glial Regulation of Neurotransmitter Turnover}

In addition to ion homeostasis, vertebrate and invertebrate glia express a suite of receptors and transporters for uptake of neurotransmitters including glutamate, acetylcholine, and GABA, as well as neuromodulators such as histamine (van der Zee et al., 1993; Ribak et al., 1996; Stacey et al., 2010; Schousboe et al., 2013; Allen, 2014; Chaturvedi et al., 2014; Muthukumar et al., 2014; Boddum et al., 2016; Katz et al., 2019; Peng et al., 2019; Singhvi and Shaham, 2019; Zhang et al., 2019). Continual recycling of neurotransmitters by perisynaptic glia, primarily astrocytes, is necessary for prolonged synaptic function. Neurotransmitter uptake serves to prevent ectopic crosstalk between neighboring synapses, but also to avert excitotoxicity due to accumulation of perisynaptic glutamate (Murphy-Royal et al., 2017). Once taken up by astrocytes, glutamate enters the glutamate-glutamine cycle. In this cycle, glutamine synthase converts glutamate into glutamine for subsequent release and uptake by neurons. Because glutamine is a metabolic precursor for both glutamate and GABA, this is essential for continued function of the predominant excitatory and inhibitory synapse types within the brain (Schousboe et al., 2013; Allen, 2014). Interestingly, a recent report found that oligodendrocytes within caudal regions of the brain and spinal cord also express glutamine synthetase. Following oligodendrocyte-specific knockout of glutamine synthetase, synaptic glutamate transmission in the midbrain was significantly impaired due to overall reductions in both glutamate and glutamine (Xin et al., 2019). Thus, in the
CNS, both oligodendrocytes and astrocytes mediate continued turnover of glutamate.

\section{Glial-Mediated Synaptic Dysfunction in Disease}

Loss of ionic and neurotransmitter homeostasis disrupts synaptic maintenance and synaptic function, and has consequently been linked to a number of neurological disorders. Mutations in KCNJ10, which encodes human Kir4.1, causes SeSAME/EAST syndrome. SeSAME/EAST is a neurodevelopmental disorder associated with a variety of phenotypes including ataxia, seizures, deafness, and intellectual disability (Scholl et al., 2009). Furthermore, mutations in KCNJ10 are linked to increased risk for seizure and ataxia in other neurodevelopmental disorders such as autism and Rett's syndrome, underscoring the importance of glial ion buffering to developmental circuit function (Nwaobi et al., 2016; Eid et al., 2019). Interestingly, though mutations in KCNJ10 have not been linked to neurodegenerative disorders, analysis of animal models of $\mathrm{AD}$, amyotrophic lateral sclerosis (ALS), and Huntington's disease suggest that downregulation of Kir4.1 in astrocytes may contribute to disease onset and/or progression (Kaiser et al., 2006; Wilcock et al., 2009; Tong et al., 2014). Indeed, post-mortem brain samples from AD patients with severe cerebral amyloid angiopathy showed loss of Kir4.1 from astrocytic endfeet (Wilcock et al., 2009). Altered neurotransmitter turnover is also linked to neurodevelopmental and neurodegenerative disorders (Murphy-Royal et al., 2017), and in some cases, impaired ion and neurotransmitter turnover converge in disease. As aforementioned, astrocytic Kir4.1 is also needed for appropriate uptake of perisynaptic glutamate by GLT1 (Djukic et al., 2007). Expression of GLT-1 is downregulated in post-mortem brains of Huntington's disease patients (Arzberger et al., 1997). Similarly, expression of Kir4.1 is also significantly reduced in animal models of Huntington's disease. Excitingly, overexpression of Kir4.1 in striatal astrocytes rescues Glt-1 expression deficits, improves function of medium spiny neurons (disproportionately lost in Huntington's disease) and increases animal survival (Tong et al., 2014). As Kir4.1 is affected in a vast array of neurological disorders and modifies multiple critical functions of astrocytes, identifying therapeutic strategies that target Kir4.1 function could have extensive medical impact.

Outside of the CNS, loss of glial support disrupts synaptic maintenance and overall peripheral nerve health. In vertebrates, tSCs are required for maintenance of the NMJ, and loss of tSCs (Santosa et al., 2018) or neuron-glial signaling (JablonkaShariff et al., 2020) can result in degeneration. Similarly, post-developmental ablation of $C$. elegans AMsh glia (exhibit ensheathment similar to non-myelinating Schwann cells) results in retraction of neuron receptive endings (pre-synaptic) that sense the environment (Bacaj et al., 2008; Singhvi et al., 2016; Wallace et al., 2016). Disruption of glia-derived ion transporters does not only impact synaptic maintenance but can disrupt peripheral nerve health. Loss of NKCC1 homologs $\left(\mathrm{Na}^{+}, \mathrm{K}^{+}\right.$, and $\mathrm{Cl}^{-}$cotransporter) from peripheral glia results in abnormal nerve swelling and axonal defasciculation in Drosophila (Leiserson et al., 2000, 2011) and zebrafish (Marshall-Phelps et al., 2020), 
resulting in neuropathy-like symptoms (Leiserson et al., 2000, 2011; Marshall-Phelps et al., 2020). In sum, glia support overall nervous system health by careful management of the extracellular environment.

\section{GLIAL REGULATION OF NERVOUS SYSTEM FUNCTION}

\section{Metabolic Support of Neurons by Glia}

Glia instruct nervous system function beyond the synaptic unit. Neuronal signaling is energetically demanding, yet energy stores (e.g., glucose) within the blood are largely inaccessible to neurons due to blood-brain and blood-nerve barriers (Poduslo et al., 1994; Daneman and Prat, 2015). Both central and peripheral glia, which more directly interact with vasculature, respond to the metabolic states of neurons and provide critical metabolic support for continued nervous system function. This role of glia was first described in the honeybee retina (Tsacopoulos and Poitry, 1982; Tsacopoulos et al., 1987, 1988) and later for Müller glia in the rodent retina (Poitry-Yamate and Tsacopoulos, 1992; Poitry-Yamate et al., 1995). This process converges on a glia-toneuron lactate shuttle following glycolysis, regardless of system (invertebrate vs. vertebrate) or cell type (Fünfschilling et al., 2012; Lee et al., 2012; Beirowski et al., 2014; Pooya et al., 2014; Volkenhoff et al., 2015; Saab et al., 2016; Philips and Rothstein, 2017; Delgado et al., 2018; Yildirim et al., 2019; Deitmer et al., 2019; Bouçanova and Chrast, 2020). Astrocytes, which form an integral component of the neurovascular unit, are also known to shuttle lactate to neurons in both animal models and in the human brain (Pellerin and Magistretti, 1994; Svichar and Chesler, 2003; Mangia et al., 2009; Deitmer et al., 2019). According to the Astrocyte-to-Neuron Lactate Shuttle hypothesis (Pellerin and Magistretti, 1994), glucose passes through transporters between capillaries and astrocytes; it is ultimately converted from pyruvate to lactate following glycolysis, and transported into neurons through monocarboxylate transporters (MCTs). Once inside the neuron, lactate reverts back to pyruvate via lactate dehydrogenases for use in aerobic respiration within mitochondria (Steinman et al., 2016; Deitmer et al., 2019). This process is elegantly coupled to glutamate release from neighboring synapses, ensuring that energy supply meets demand (Pellerin and Magistretti, 1994). Similarly, blood brain barrier glia in Drosophila transfer lactate from the haemolymph to neurons in the CNS via the MCT chaski, and loss of chaski from glia disrupts excitatory synaptic transmission and locomotion (Delgado et al., 2018).

In CNS white matter and in peripheral nerves, metabolic support of axons is carried out by myelinating oligodendrocytes and Schwann cells, respectively (Fünfschilling et al., 2012; Philips and Rothstein, 2017; Bouçanova and Chrast, 2020). The myelin sheath is organized into multiple functional domains, including cytoplasmic (myelinic) channels that facilitate uptake of metabolites and ions from neighboring astrocytes (for oligodendrocytes) or from the environment (both oligodendrocytes and Schwann cells), which can then be transferred to the associated axonal segment (Lutz et al., 2009;
Salzer, 2015; Snaidero et al., 2017). Given that mutations in many genes enriched in myelinating glia (e.g., PLP, CNPase, and MPZ) cause axonal degeneration in the absence of overt dysmyelination (Philips and Rothstein, 2017; Bouçanova and Chrast, 2020), this function of oligodendrocytes and Schwann cells is distinct from the role of myelin in saltatory conduction (discussed below in section "Myelination and Circuit Function"). In the CNS, oligodendrocytes take in extracellular glucose, which is then converted to lactate and transferred to neurons via the monocarboxylate transporter MCT1 (Lee et al., 2012). Accordingly, oligodendrocyte-specific knockout of MCT1 in vitro within mouse organotypic spinal cord slice cultures, or in vivo within the optic nerve and corpus callosum, causes axonopathy prior to myelin damage (Lee et al., 2012). A recent report found that glucose uptake by oligodendrocytes can be stimulated by binding of glutamate to oligodendrocyte NMDA receptors (Saab et al., 2016). These findings suggest that oligodendrocyte-specific metabolic support, as with astrocytic support, is coupled to neuronal output. In the PNS, disruption of glial metabolism and mitochondrial homeostasis via Schwann cell-specific knockout of the serine/threonine kinase LKB1 causes a severe, progressive axonopathy reminiscent of diabetic neuropathy (Beirowski et al., 2014). Thus, glia ensure energy demand is met for proper nervous system homeostasis.

\section{Myelination and Circuit Function}

Even when ionic and metabolic conditions are met, circuits within the vertebrate nervous system cannot function without myelin. Myelin is a multi-lamellar sheath generated by oligodendrocytes in the CNS and Schwann cells in the PNS (Salzer, 2015; Ackerman and Monk, 2016; Simons and Nave, 2016). Myelin promotes saltatory conduction through insulation of axonal segments and clustering of ion channels at nodes of Ranvier (discussed further in Rasband and Peles, 2015). Myelin thickness is highly stereotyped, and mutations that either increase (hyper) or decrease (hypo) myelin thickness or alter myelin sheath length, can adversely affect action potential propagation (Court et al., 2004; Michailov et al., 2004; Simpson et al., 2013; Li, 2015; Etxeberria et al., 2016; Camargo et al., 2017). These data suggest that myelin state must be tightly regulated. A 3D TEM reconstruction of myelinated segments along pyramidal neurons in the mouse neocortex demonstrated extensive variability in the extent and pattern of myelination along axon tracts, leading to the hypothesis that oligodendrocytes dynamically respond to, and modify, circuit activity (Tomassy et al., 2014). In the past decade, a number of studies demonstrated that neuronal activity tunes the level of oligodendrocyte myelination in vivo (Monje, 2018). In zebrafish, silencing of reticulospinal neurons or phox $2 b+$ hindbrain neurons via expression of tetanus toxin biased axon selection to electrically active neighbors (Hines et al., 2015; Mensch et al., 2015). Pharmacological activation of reticulospinal neurons also enhanced axon selection, which could be blocked by expression of tetanus toxin. This finding suggests that oligodendrocytes monitor neuronal activity through release of local synaptic vesicles (Mensch et al., 2015). Indeed, a recent report demonstrated that oligodendrocytes express post-synaptic 
proteins, putative sites of axon-glial communication, which are necessary to tune sheath length and number (Hines et al., 2015; Hughes and Appel, 2019). In mouse, oligodendrocyte myelination is also regulated by neuronal activity (Gibson et al., 2014; Etxeberria et al., 2016; Swire et al., 2019; Bacmeister et al., 2020). Optogenetic activation of deep cortical projection neurons of the premotor cortex is sufficient to stimulate oligodendrocyte precursor cell proliferation, enhance myelination, and improve motor learning (Gibson et al., 2014). In contrast, neuronal silencing by monocular deprivation caused myelin internode length in the optic nerve to be significantly shorter, resulting in reduced nerve conduction velocity (Etxeberria et al., 2016). Together, these data exhibit that myelin is much more dynamic than previously appreciated, and that myelin plasticity can shape circuit function.

\section{Glia and Neural Circuit Function}

Finally, glia instruct circuit function through modulating activitydependent plasticity mechanisms that function both locally (synapse-level) and globally (circuit-level). As this subject has been reviewed extensively, here we will direct readers to relevant literature (Araque et al., 2014; Wu et al., 2015; Allen and Eroglu, 2017; Salter and Stevens, 2017; Babola et al., 2018; Long et al., 2018; Bar and Barak, 2019; Durkee and Araque, 2019; Foster et al., 2019; Marinelli et al., 2019; Mederos and Perea, 2019; Ackerman et al., 2020), and instead highlight two pertinent examples of astrocyte-mediated neuromodulation in fly (Ma et al., 2016) and zebrafish (Mu et al., 2019). Astrocytes display local and population-wide calcium transients in response to changes in neuronal activity, and it is thought that these transients may in turn influence circuit function (Fatatis and Russell, 1992; Porter and McCarthy, 1996; Nett et al., 2002; Nimmerjahn et al., 2009; Srinivasan et al., 2015). In a landmark study, Ma et al. (2016) identified TRP channel Waterwitch (Wtrw) activity and octopamine-tyramine receptor (Oct-TyrR) signaling as key mediators of astrocyte-dependent neuromodulation. Drosophila astrocytes within the ventral nerve cord exhibit oscillatory waves of calcium activity in response to neuronal activity. Here, the authors found that octopamine and tyramine signaling (analogous to vertebrate norepinephrine) from $\mathrm{Tdc} 2+$ neurons in the ventral nerve cord activates OctTyrR on astrocytes, which in turn allows for calcium entry via Wtrw. Calcium influx drives secretion of an astrocytederived cue (potentially ATP) that inhibits adenosine receptors on local dopaminergic neurons, which is necessary for proper larval chemotaxis and startle behavior. Thus, astrocyte-mediated neuromodulation occurs in vivo, is necessary for circuit function, and drives animal behavior (Ma et al., 2016).

Until recently, evidence of bona fide astrocytes, with their characteristic stellate structure, was lacking in zebrafish (Lyons and Talbot, 2015; Mu et al., 2019; Chen et al., 2020). Instead, radial glia were believed to perform astrocytic functions in zebrafish (Kroehne et al., 2011; Kyritsis et al., 2012). Excitingly, a recent study showed that a subtype of astrocytes in zebrafish called radial astrocytes are actively engaged in neural computation in vivo within a behaviorally relevant circuit. Futility-induced passivity ("giving up") is a strategy that allows animals to conserve energy following repeated failed attempts to achieve a given task (Maier, 1984; Warden et al., 2012). In this pioneering work, $\mathrm{Mu}$ et al. (2019) developed a virtual reality arena that would induce visually evoked, perceived swimming failures. Using whole-brain calcium imaging to simultaneously monitor neuronal and glial calcium levels, they found that repeated swimming failures resulted in accumulation of calcium in radial astrocytes that reside within the lateral medulla oblongata. Localized ablation of radial astrocytes or disruption of astrocytic calcium signaling using an IP3R inhibitor (xestospongin C) strongly suppressed futility-induced passivity, but not wildtype swimming behavior. Through further circuit analysis, the authors demonstrate that radial astrocytes signal via an unknown mechanism to activate downstream GABAergic neurons within the lateral medulla oblongata and suppress continued motor output. Interestingly, accumulation of calcium within radial astrocytes is also dependent on norepinephrine signaling from neurons within the norepinephrine expressing cluster of the medulla oblongata ( $\mathrm{Mu}$ et al., 2019). Recently, cells resembling mammalian spinal cord astrocytes in every aspect (stellate morphology, marker expression, and calcium signaling) were described in zebrafish for the first time, and were also shown to be norepinephrine sensitive (Chen et al., 2020). These studies together suggest that norepinephrine signaling from neurons may be a common trigger for astrocytemediated neuromodulation (Paukert et al., 2014; Ma et al., 2016; Mu et al., 2019).

\section{Glia and Circuit Dysfunction in Disease}

It is evident that glial cells strongly contribute to circuit function. Accordingly, glial cell dysfunction is present in a variety of neurodevelopmental disorders that impact neural network activity (Ma et al., 2016; Mondelli et al., 2017; Salter and Stevens, 2017). This is particularly apparent in neural networks that exhibit higher than average levels of neuronal activity and therefore have greater energetic demands. Motor neurons are highly polarized and energetically demanding cells that extend axons in excess of a meter in length in humans. Accordingly, they require extensive metabolic support from glial cells for continued function and survival (Van Damme et al., 2002; Bélanger et al., 2011; Lee et al., 2012; Morrison et al., 2013; Bouçanova et al., 2020). Amyotrophic lateral sclerosis (ALS) is a progressive neurodegenerative disorder characterized by specific loss of lower and upper motor neurons in the spine and motor cortex, respectively, resulting in paralysis and mortality within $\sim 5$ years of disease onset. Though the majority of ALS cases are non-hereditary (sporadic), 10\% of ALS cases are familial in nature and are mapped to known disease-causing loci. Most familial ALS cases are caused by mutations in a handful of genes including SOD1, Tpd43, Fus, and C9orf72 (Robberecht and Philips, 2013). By modeling ALS in animal models using celltype specific manipulations (Pramatarova et al., 2001; Lino et al., 2002; Beers et al., 2006; Boillée et al., 2006b; Haidet-Phillips et al., 2011; Wang et al., 2011; Kang et al., 2013; Lee and Sun, 2015; Bouçanova et al., 2020), it became clear that glial cells strongly contribute to both disease onset and progression (Boillée et al., 2006a; Philips and Rothstein, 2014; Yamanaka and Komine, 2018; 
Filipi et al., 2020). For example, in chimeric mice, disease onset is delayed when mutant SOD1 motor neurons are surrounded and supported by wildtype glial cells (Clement et al., 2003).

Analysis of human tissue revealed that microglial and astrocyte populations adopt activated, pro-inflammatory states locally and systemically in ALS (McCombe and Henderson, 2011; Robberecht and Philips, 2013; Blasco et al., 2017; McCauley and Baloh, 2019). This switch in cell state adversely impacts motor neuron survival through the combined cytotoxic effects of inflammation and a loss of homeostatic functions, such as neurotransmitter turnover (Liddelow et al., 2017). Astrocytes are necessary for glutamate clearance from the synaptic cleft (Allen, 2014). Downregulation of the glutamate transporter EAAT2 is evident in animal models expressing mutant SOD $1^{G 93 A}$ (Howland et al., 2002; Boston-Howes et al., 2006), which could be rescued in part via glutamate uptake by focal transplantation of wildtype astrocytes (Lepore et al., 2008). This change in expression causes aberrant accumulation of perisynaptic glutamate, which results in glutamate induced excitotoxicity (Filipi et al., 2020). In the healthy nervous system, astrocytes position mitochondria at places with high energetic demand (Agarwal et al., 2017), because glial transfer of lactate is coupled to extracellular levels of glutamate (Pellerin and Magistretti, 1994). MCT1 expression in oligodendroglia is similarly downregulated in models and patients with mutant SOD1, suggesting that glutamate-induced excitoxicity may be compounded by a lack of glia-mediated metabolic support (Lee et al., 2012). A recent study found that suppressing astrocyte activation and subsequent astrogliosis significantly prolonged the lifespan of a mouse model of ALS (SOD1 $1^{G 93 A}$ ), implicating gliosis as a putative target for therapeutic intervention (Guttenplan et al., 2020).

\section{CONCLUDING REMARKS ON GLIA AS THERAPEUTIC TARGETS IN DISEASE}

To summarize, the nervous system contains a variety of glial cell types that collectively orchestrate neural development and ensure continued nervous system function. The field of glial biology has long focused on how individual glial subtypes influence neuronal health and longevity. Thus, we have achieved a great deal of success in delineating how disruptions to single glial cell populations contribute to pathology in various animal models

\section{REFERENCES}

Aarum, J., Sandberg, K., Haeberlein, S. L. B., and Persson, M. A. A. (2003). Migration and differentiation of neural precursor cells can be directed by microglia. Proc. Natl. Acad. Sci. U.S.A. 100, 15983-15988. doi: 10.1073/pnas. 2237050100

Ackerman, S. D., and Monk, K. R. (2016). The scales and tales of myelination: using zebrafish and mouse to study myelinating glia. Brain Res. 1641, 79-91. doi: 10.1016/j.brainres.2015.10.011

Ackerman, S. D., Perez-Catalan, N. A., Freeman, M. R., and Doe, C. Q. (2020). Astrocytes close a critical period of motor circuit plasticity. bioRxiv [Preprint]. doi: $10.1101 / 2020.05 .15 .098608$ of disease. As neurological disease states are often accompanied by dysfunction in multiple glial populations, it is unsurprising that therapeutic interventions that target individual glial and neuronal populations have been met with limited success. Furthermore, it is increasingly evident that in addition to glianeuron interactions, dynamic glial-glial communication instructs development and function of the healthy and diseased nervous system. Generation of complementary genetic strategies that facilitate independent manipulation of multiple cell populations in vertebrates, while leveraging invertebrate models that are already amenable to complex genetics approaches, is necessary to understand how different glial subtypes function in concert with one another in vivo. By expanding the scope of our experiments to account for the complexity of these interactions, we have the potential to uncover novel therapeutic strategies to simultaneously inhibit glial inflammation and promote glial homeostatic functions to drive repair and recovery.

\section{AUTHOR CONTRIBUTIONS}

SA and VF conceived the topic. IL-B prepared the figures and together with VF and SA and wrote sections "Introduction" to "Glia in Neuronal Migration and Pathfinding of Axons and Dendrites." SA wrote sections "Glial Regulation of Synapse Numbers" to "Concluding Remarks on Glia as Therapeutic Targets in Disease" with comments from IL-B and VF. All authors contributed to the article and approved the submitted version.

\section{FUNDING}

This project was funded by the Wellcome Trust and Royal Society Sir Henry Dale Research Fellowship (210472/Z/18/A) to VF and by the NIH/NINDS to SA (F32NS098690). SA was a Milton Safenowitz Postdoctoral Fellow of the ALS Association.

\section{ACKNOWLEDGMENTS}

We are grateful to Victoria Rook and Robert Rowe for their help with figure design. We would also like to thank Maria Purice and Richard Poole for their guidance with respect to homologous functions of C. elegans glia.

Adelman, L. S., and Aronson, S. M. (1972). Intramedullary nerve fiber and Schwann cell proliferation within the spinal cord (schwannosis). Neurology 22, 726-731. doi: 10.1212/wnl.22.7.726

Agarwal, A., Wu, P. H., Hughes, E. G., Fukaya, M., Tischfield, M. A., Langseth, A. J., et al. (2017). Transient opening of the mitochondrial permeability transition pore induces microdomain calcium transients in astrocyte processes. Neuron 93, 587-605.e7. doi: 10.1016/j.neuron.2016.12.034

Allen, N. J. (2014). Astrocyte regulation of synaptic behavior. Annu. Rev. Cell Dev. Biol. 30, 439-463. doi: 10.1146/annurev-cellbio-100913013053

Allen, N. J., and Eroglu, C. (2017). Cell biology of astrocyte-synapse interactions. Neuron 96, 697-708. doi: 10.1016/j.neuron.2017.09.056 
Allen, N. J., and Lyons, D. A. (2018). Glia as architects of central nervous system formation and function. Science 185, 181-185. doi: 10.1126/science.aat0473

Alvarez-Buylla, A., Kohwi, M., Nguyen, T. M., and Merkle, F. T. (2008). The heterogeneity of adult neural stem cells and the emerging complexity of their niche. Cold Spring Harb. Symp. Quant. Biol. 73, 357-365. doi: 10.1101/sqb.2008. 73.019

Antony, J. M., Paquin, A., Nutt, S. L., Kaplan, D. R., and Miller, F. D. (2011). Endogenous microglia regulate development of embryonic cortical precursor cells. J. Neurosci. Res. 89, 286-298. doi: 10.1002/jnr.22533

Araque, A., Carmignoto, G., Haydon, P. G., Oliet, S. H. R., Robitaille, R., and Volterra, A. (2014). Gliotransmitters travel in time and space. Neuron 81, 728-739. doi: 10.1016/j.neuron.2014.02.007

Arzberger, T., Krampfl, K., Leimgruber, S., and Weindl, A. (1997). Changes of NMDA receptor subunit (NR1, NR2B) and glutamate transporter (GLT1) mRNA expression in Huntington's disease - an in situ hybridization study. J. Neuropathol. Exp. Neurol. 56, 440-454. doi: 10.1097/00005072-19970400000013

Ashton, R. S., Conway, A., Pangarkar, C., Bergen, J., Lim, K. I., Shah, P., et al. (2012). Astrocytes regulate adult hippocampal neurogenesis through ephrin-B signaling. Nat. Neurosci. 15, 1399-1406. doi: 10.1038/nn.3212

Avraham, O., Deng, P.-Y., Jones, S., Kuruvilla, R., Semenkovich, C. F., Klyachko, V. A., et al. (2020). Satellite glial cells promote regenerative growth in sensory neurons. bioRxiv [Preprint]. doi: 10.1101/2019.12.13.874669

Awasaki, T., Tatsumi, R., Takahashi, K., Arai, K., Nakanishi, Y., Ueda, R., et al. (2006). Essential role of the apoptotic cell engulfment genes draper and ced-6 in programmed axon pruning during Drosophila metamorphosis. Neuron 50, 855-867. doi: 10.1016/j.neuron.2006.04.027

Babola, T. A., Kersbergen, C. J., Wang, H. C., and Bergles, D. E. (2020). Purinergic signaling in cochlear supporting cells reduces hair cell excitability by increasing the extracellular space. eLife 9:e52160. doi: 10.7554/eLife.52160

Babola, T. A., Li, S., Gribizis, A., Lee, B. J., Issa, J. B., Wang, H. C., et al. (2018). Homeostatic control of spontaneous activity in the developing auditory system. Neuron 99, 511-524.e5. doi: 10.1016/j.neuron.2018.07.004

Bacaj, T., Tevlin, M., Lu, Y., and Shaham, S. (2008). Glia are essential for sensory organ function in C. elegans. Science 322, 744-747. doi: 10.1126/science. 1163074

Bacmeister, C. M., Barr, H. J., McClain, C. R., Thornton, M. A., Nettles, D., Welle, C. G., et al. (2020). Motor learning promotes remyelination via new and surviving oligodendrocytes. Nat. Neurosci. 23, 819-831. doi: 10.1038/s41593020-0637-3

Bar, E., and Barak, B. (2019). Microglia roles in synaptic plasticity and myelination in homeostatic conditions and neurodevelopmental disorders. Glia 67, 21252141. doi: 10.1002/glia.23637

Barkho, B. Z., Song, H., Aimone, J. B., Smrt, R. D., Kuwabara, T., Nakashima, K., et al. (2006). Identification of astrocyte-expressed factors that modulate neural stem/progenitor cell differentiation. Stem Cells Dev. 15, 407-421. doi: $10.1089 / \mathrm{scd} .2006 .15 .407$

Barraud, P., St John, J. A., Stolt, C. C., Wegner, M., and Baker, C. V. H. (2013). Olfactory ensheathing glia are required for embryonic olfactory axon targeting and the migration of gonadotropin-releasing hormone neurons. Biol. Open 2, 750-759. doi: 10.1242/bio.20135249

Barresi, M. J. F., Hutson, L. D., Chien, C. B., and Karlstrom, R. O. (2005). Hedgehog regulated Slit expression determines commissure and glial cell position in the zebrafish forebrain. Development 132, 3643-3656. doi: 10.1242/dev.01929

Bayraktar, O. A., Bartels, T., Holmqvist, S., Kleshchevnikov, V., Martirosyan, A., Polioudakis, D., et al. (2020). Astrocyte layers in the mammalian cerebral cortex revealed by a single-cell in situ transcriptomic map. Nat. Neurosci. 23, 500-509. doi: 10.1038/s41593-020-0602-1

Bayraktar, O. A., Fuentealba, L. C., Alvarez-Buylla, A., and Rowitch, D. H. (2014). Astrocyte development and heterogeneity. Cold Spring Harb. Perspect. Biol. 7:a020362. doi: 10.1101/cshperspect.a020362

Beattie, R., and Hippenmeyer, S. (2017). Mechanisms of radial glia progenitor cell lineage progression. FEBS Lett. 591, 3993-4008. doi: 10.1002/1873-3468.12906

Beers, D. R., Henkel, J. S., Xiao, Q., Zhao, W., Wang, J., Yen, A. A., et al. (2006). Wild-type microglia extend survival in PU.1 knockout mice with familial amyotrophic lateral sclerosis. Proc. Natl. Acad. Sci. U.S.A. 103, 16021-16026. doi: $10.1073 /$ pnas. 0607423103
Beirowski, B., Babetto, E., Golden, J. P., Chen, Y. J., Yang, K., Gross, R. W., et al. (2014). Metabolic regulator LKB1 is crucial for Schwann cellmediated axon maintenance. Nat. Neurosci. 17, 1351-1361. doi: 10.1038/nn. 3809

Bejarano-Escobar, R., Sánchez-Calderón, H., Otero-Arenas, J., Martín-Partido, G., and Francisco-Morcillo, J. (2017). Müller glia and phagocytosis of cell debris in retinal tissue. J. Anat. 231, 471-483. doi: 10.1111/joa.12653

Bélanger, M., Allaman, I., and Magistretti, P. J. (2011). Brain energy metabolism: focus on Astrocyte-neuron metabolic cooperation. Cell Metab. 14, 724-738. doi: 10.1016/j.cmet.2011.08.016

Bershteyn, M., Nowakowski, T. J., Pollen, A. A., Di Lullo, E., Nene, A., WynshawBoris, A., et al. (2017). Human iPSC-derived cerebral organoids model cellular features of Lissencephaly and reveal prolonged mitosis of outer radial glia. Cell Stem Cell 20, 435-449.e4. doi: 10.1016/j.stem.2016.12.007

Bialas, A. R., and Stevens, B. (2013). TGF- $\beta$ signaling regulates neuronal C1q expression and developmental synaptic refinement. Nat. Neurosci. 16, 17731782. doi: $10.1038 / \mathrm{nn} .3560$

Bittern, J., Pogodalla, N., Ohm, H., Brüser, L., Kottmeier, R., Schirmeier, S., et al. (2020). Neuron-glia interaction in the Drosophila nervous system. Dev. Neurobiol. 1-15. doi: 10.1002/dneu.22737

Bjornsson, C. S., Apostolopoulou, M., Tian, Y., and Temple, S. (2015). It takes a village: constructing the neurogenic niche. Dev. Cell 32, 435-446. doi: 10.1016/ j.devcel.2015.01.010

Blakemore, W. F., and Patterson, R. C. (1975). Observations on the interactions of Schwann cells and astrocytes following X-irradiation of neonatal rat spinal cord. J. Neurocytol. 4, 573-585. doi: 10.1007/BF01351538

Blasco, H., Garcon, G., Patin, F., Veyrat-Durebex, C., Boyer, J., Devos, D., et al. (2017). Panel of oxidative stress and inflammatory biomarkers in ALS: a pilot study. Can. J. Neurol. Sci. 44, 90-95. doi: 10.1017/cjn.2016.284

Boddum, K., Jensen, T. P., Magloire, V., Kristiansen, U., Rusakov, D. A., Pavlov, I., et al. (2016). Astrocytic GABA transporter activity modulates excitatory neurotransmission. Nat. Commun. 7:13572. doi: 10.1038/ncomms13572

Boillée, S., Vande Velde, C., and Cleveland, D. W. W. (2006a). ALS: a disease of motor neurons and their nonneuronal neighbors. Neuron 52, 39-59. doi: 10.1016/j.neuron.2006.09.018

Boillée, S., Yamanaka, K., Lobsiger, C. S., Copeland, N. G., Jenkins, N. A., Kassiotis, G., et al. (2006b). Onset and progression in inherited ALS determined by motor neurons and microglia. Science 312, 1389-1392. doi: 10.1126/science.1123511

Bonzano, S., Crisci, I., Podlesny-Drabiniok, A., Rolando, C., Krezel, W., Studer, M., et al. (2018). Neuron-Astroglia cell fate decision in the adult mouse hippocampal neurogenic niche is cell-intrinsically controlled by COUP-TFI in vivo. Cell Rep. 24, 329-341. doi: 10.1016/j.celrep.2018.06.044

Boston-Howes, W., Gibb, S. L., Williams, E. O., Pasinelli, P., Brown, R. H., and Trotti, D. (2006). Caspase-3 cleaves and inactivates the glutamate transporter EAAT2. J. Biol. Chem. 281, 14076-14084. doi: 10.1074/jbc.M600653200

Bouçanova, F., and Chrast, R. (2020). Metabolic interaction between Schwann cells and axons under physiological and disease conditions. Front. Cell. Neurosci. 14:148. doi: 10.3389/fncel.2020.00148

Bouçanova, F., Pollmeier, G., Sandor, K., Morado Urbina, C., Nijssen, J., Médard, J. J., et al. (2020). Disrupted function of lactate transporter MCT1, but not MCT4, in Schwann cells affects the maintenance of motor end-plate innervation. Glia 69, 124-136. doi: 10.1002/glia.23889

Bredesen, D. E., Rao, R. V., and Mehlen, P. (2006). Cell death in the nervous system. Nature 443, 796-802. doi: 10.1038/nature05293

Brenner, M., Johnson, A. B., Boespflug-Tanguy, O., Rodriguez, D., Goldman, J. E., and Messing, A. (2001). Mutations in GFAP, encoding glial fibrillary acidic protein, are associated with Alexander disease. Nat. Genet. 27, 117-120. doi: $10.1038 / 83679$

Britton, J. S., and Edgar, B. A. (1998). Environmental control of the cell cycle in Drosophila: nutrition activates mitotic and endoreplicative cells by distinct mechanisms. Development 125, 2149-2158.

Brody, T., and Odenwald, W. F. (2002). Cellular diversity in the developing nervous system: a temporal view from Drosophila. Development 129, 3763-3770.

Bron, R., Vermeren, M., Kokot, N., Andrews, W., Little, G. E., Mitchell, K. J., et al. (2007). Boundary cap cells constrain spinal motor neuron somal migration at motor exit points by a semaphorin-plexin mechanism. Neural Dev. 2:21. doi: 10.1186/1749-8104-2-21 
Buchsbaum, I. Y., and Cappello, S. (2019). Neuronal migration in the CNS during development and disease: insights from in vivo and in vitro models. Development 146:dev163766. doi: 10.1242/dev.163766

Burek, M. J., and Oppenheim, R. W. (1996). Programmed cell death in the developing nervous system. Brain Pathol. 6, 427-446. doi: 10.1111/j.1750-3639. 1996.tb00874.x

Buss, R. R., Sun, W., and Oppenheim, R. W. (2006). Adaptive roles of programmed cell death during nervous system development. Annu. Rev. Neurosci. 29, 1-35. doi: 10.1146/annurev.neuro.29.051605.112800

Calderó, J., Brunet, N., Ciutat, D., Hereu, M., and Esquerda, J. E. (2009). Development of microglia in the chick embryo spinal cord: implications in the regulation of motoneuronal survival and death. J. Neurosci. Res. 87, 2447-2466. doi: 10.1002/jnr.22084

Callan, M. A., Clements, N., Ahrendt, N., and Zarnescu, D. C. (2012). Fragile $\mathrm{X}$ Protein is required for inhibition of insulin signaling and regulates glialdependent neuroblast reactivation in the developing brain. Brain Res. 1462, 151-161. doi: 10.1016/j.brainres.2012.03.042

Camargo, N., Goudriaan, A., van Deijk, A. L. F., Otte, W. M., Brouwers, J. F., Lodder, H., et al. (2017). Oligodendroglial myelination requires astrocytederived lipids. PLoS Biol. 15:e1002605. doi: 10.1371/journal.pbio.1002605

Caviness, V. S. (1982). Neocortical histogenesis in normal and reeler mice: a developmental study based upon $[3 \mathrm{H}]$ thymidine autoradiography. Dev. Brain Res. 4, 293-302. doi: 10.1016/0165-3806(82)90141-9

Chaturvedi, R., Reddig, K., and Li, H. S. (2014). Long-distance mechanism of neurotransmitter recycling mediated by glial network facilitates visual function in Drosophila. Proc. Natl. Acad. Sci. U.S.A. 111, 2812-2817. doi: 10.1073/pnas. 1323714111

Cheadle, L., Rivera, S. A., Phelps, J. S., Ennis, K. A., Stevens, B., Burkly, L. C., et al. (2020). Sensory experience engages microglia to shape neural connectivity through a non-phagocytic mechanism. Neuron 108, 451-468.e9. doi: 10.1016/j. neuron.2020.08.002

Chell, J. M., and Brand, A. H. (2010). Nutrition-responsive glia control exit of neural stem cells from quiescence. Cell 143, 1161-1173. doi: 10.1016/j.cell.2010. 12.007

Chen, J., Poskanzer, K. E., Freeman, M. R., and Monk, K. R. (2020). Live-imaging of astrocyte morphogenesis and function in zebrafish neural circuits. Nat. Neurosci. 23, 1297-1306. doi: 10.1038/s41593-020-0703-x

Chotard, C., Leung, W., and Salecker, I. (2005). glial cells missing and gcm2 cell autonomously regulate both glial and neuronal development in the visual system of Drosophila. Neuron 48, 237-251. doi: 10.1016/j.neuron.2005.09.019

Chotard, C., and Salecker, I. (2004). Neurons and glia: team players in axon guidance. Trends Neurosci. 27, 655-661. doi: 10.1016/j.tins.2004.09.001

Chotard, C., and Salecker, I. (2007). Glial cell development and function in the Drosophila visual system. Neuron Glia Biol. 3, 17-25. doi: 10.1017/ S1740925X07000592

Chung, W., Allen, N. J., and Eroglu, C. (2015). Astrocytes control synapse formation, function, and elimination. Cold Spring Harb. Perspect. Biol. 7:a020370. doi: 10.1101/cshperspect.a020370

Chung, W., Clarke, L. E., Wang, G. X., Stafford, B. K., Sher, A., Chakraborty, C., et al. (2013). Astrocytes mediate synapse elimination through MEGF10 and MERTK pathways. Nature 504, 394-400. doi: 10.1038/nature12776

Clark, J. K., O'keefe, A., Mastracci, T. L., Sussel, L., Matise, M. P., and Kucenas, S. (2014). Mammalian Nkx2.2+ perineurial glia are essential for motor nerve development. Dev. Dyn. 243, 1116-1129. doi: 10.1002/dvdy.24158

Clement, A. M., Nguyen, M. D., Roberts, E. A., Garcia, M. L., Boillée, S., Rule, M., et al. (2003). Wild-type nonneuronal cells extend survival of SOD1 mutant motor neurons in ALS mice. Science 302, 113-117. doi: 10.1126/science. 1086071

Colón-Ramos, D. A., Margeta, M. A., and Shen, K. (2007). Glia promote local synaptogenesis through UNC-6 (netrin) signaling in C. elegans. Science 318, 103-106. doi: 10.1126/science. 1143762

Connor, B., Beilharz, E. J., Williams, C., Synek, B., Gluckman, P. D., Faull, R. L. M., et al. (1997). Insulin-like growth factor-I (IGF-I) immunoreactivity in the Alzheimer's disease temporal cortex and hippocampus. Mol. Brain Res. 49, 283-290. doi: 10.1016/S0169-328X(97)00192-7

Coulpier, F., Le Crom, S., Maro, G. S., Manent, J., Giovannini, M., Maciorowski, Z., et al. (2009). Novel features of boundary cap cells revealed by the analysis of newly identified molecular markers. Glia 57, 1450-1457. doi: 10.1002/glia. 20862

Court, F. A., Sherman, D. L., Pratt, T., Garry, E. M., Ribchester, R. R., Cottrell, D. F., et al. (2004). Restricted growth of Schwann cells lacking Cajal bands slows conduction in myelinated nerves. Nature 431, 191-195. doi: 10.1038/ nature 02841

Coutinho-Budd, J. C., Sheehan, A. E., and Freeman, M. R. (2017). The secreted neurotrophin spätzle 3 promotes glial morphogenesis and supports neuronal survival and function. Genes Dev. 31, 2023-2038. doi: 10.1101/gad.305888.117

Crews, F. T., McElhaney, R., Freund, G., Ballinger, W. E., and Raizada, M. K. (1992). Insulin-like growth factor I receptor binding in brains of Alzheimer's and alcoholic patients. J. Neurochem. 58, 1205-1210. doi: 10.1111/j.1471-4159. 1992.tb11330.x

Crews, S. T. (2010). Axon-glial interactions at the Drosophila CNS midline. Cell Adhes. Migr. 4, 67-71. doi: 10.4161/cam.4.1.10208

Cunningham, C. L., Martínez-Cerdeño, V., and Noctor, S. C. (2013). Microglia regulate the number of neural precursor cells in the developing cerebral cortex. J. Neurosci. 33, 4216-4233. doi: 10.1523/JNEUROSCI.3441-12.2013

Daneman, R., and Prat, A. (2015). The blood-brain barrier. Cold Spring Harb. Perspect. Biol. 7:a020412. doi: 10.1101/cshperspect.a020412

Darabid, H., Perez-Gonzalez, A. P., and Robitaille, R. (2014). Neuromuscular synaptogenesis: coordinating partners with multiple functions. Nat. Rev. Neurosci. 15, 703-718.

Deitmer, J. W., Theparambil, S. M., Ruminot, I., Noor, S. I., and Becker, H. M. (2019). Energy dynamics in the brain: contributions of astrocytes to metabolism and $\mathrm{pH}$ homeostasis. Front. Neurosci. 13:1301. doi: 10.3389/fnins.2019.01301

Delgado, M. G., Oliva, C., López, E., Ibacache, A., Galaz, A., Delgado, R., et al. (2018). Chaski, a novel Drosophila lactate/pyruvate transporter required in glia cells for survival under nutritional stress. Sci. Rep. 8:1186. doi: 10.1038/s41598018-19595-5

Diamantopoulou, E., Baxendale, S., De La Veg aDe León, A., Asad, A., Holdsworth, C. J., Abbas, L., et al. (2019). Identification of compounds that rescue otic and myelination defects in the zebrafish adgrg6 (gpr126) mutant. eLife 8:e44889. doi: 10.7554/eLife.44889

Diaz-Aparicio, I., Paris, I., Sierra-Torre, V., Plaza-Zabala, A., Rodríguez-Iglesias, N., Márquez-Ropero, M., et al. (2020). Microglia actively remodel adult hippocampal neurogenesis through the phagocytosis secretome. J. Neurosci. 40, 1453-1482. doi: 10.1523/JNEUROSCI.0993-19.2019

Dibaj, P., Kaiser, M., Hirrlinger, J., Kirchhoff, F., and Neusch, C. (2007). Kir4.1 channels regulate swelling of astroglial processes in experimental spinal cord edema. J. Neurochem. 103, 2620-2628. doi: 10.1111/j.1471-4159.2007.04979.x

Djukic, B., Casper, K. B., Philpot, B. D., Chin, L. S., and McCarthy, K. D. (2007). Conditional knock-out of Kir4.1 leads to glial membrane depolarization, inhibition of potassium and glutamate uptake, and enhanced short-term synaptic potentiation. J. Neurosci. 27, 11354-11365. doi: 10.1523/JNEUROSCI. 0723-07.2007

Doe, C. Q. (2017). Temporal patterning in the Drosophila CNS. Annu. Rev. Cell Dev. Biol. 33, 219-240. doi: 10.1146/annurev-cellbio-111315-125210

Doetsch, F., Caillé, I., Lim, D. A., Garcia-Verdugo, J. M., and Alvarez-Buylla, A. (1999). Subventricular zone astrocytes are neural stem cells in the adult mammalian brain. Cell 97, 703-716. doi: 10.1016/s0092-8674(00)80783-7

Doherty, J., Logan, M. A., Taşdemir, Ö. E., and Freeman, M. R. (2009). Ensheathing glia function as phagocytes in the adult Drosophila brain. J. Neurosci. 29, 4768-4781. doi: 10.1523/JNEUROSCI.5951-08.2009

Doherty, J., Sheehan, A. E., Bradshaw, R., Fox, A. N., Lu, T. Y., and Freeman, M. R. (2014). PI3K signaling and Stat92E converge to modulate glial responsiveness to axonal injury. PLoS Biol. 12:e1001985. doi: 10.1371/journal.pbio.1001985

Dulabon, L., Olson, E. C., Taglienti, M. G., Eisenhuth, S., McGrath, B., Walsh, C. A., et al. (2000). Reelin binds $\alpha 3 \beta 1$ integrin and inhibits neuronal migration. Neuron 27, 33-44. doi: 10.1016/S0896-6273(00)00007-6

Dulamea, A. O. (2017). "Role of oligodendrocyte dysfunction in demyelination, remyelination and neurodegeneration in multiple sclerosis," in Multiple Sclerosis: Bench to Bedside: Global Perspectives on a Silent Killer, eds A. A. A. Asea, F. Geraci, and P. Kaur (Cham: Springer), 91-127. doi: 10.1007/978-3319-47861-6_7

Dumstrei, K., Wang, F., and Hartenstein, V. (2003). Role of DE-cadherin in neuroblast proliferation, neural morphogenesis, and axon tract formation in 
Drosophila larval brain development. J. Neurosci. 23, 3325-3335. doi: 10.1523/ JNEUROSCI.23-08-03325.2003

Durkee, C. A., and Araque, A. (2019). Diversity and specificity of astrocyte-neuron communication. Neuroscience 396, 73-78. doi: 10.1016/j.neuroscience.2018. 11.010

Ebens, A. J., Garren, H., Cheyette, B. N. R., and Zipursky, S. L. (1993). The Drosophila anachronism locus: a glycoprotein secreted by glia inhibits neuroblast proliferation. Cell 74, 15-27. doi: 10.1016/0092-8674(93)90291-w

Egger, B., Gold, K. S., and Brand, A. H. (2010). Notch regulates the switch from symmetric to asymmetric neural stem cell division in the Drosophila optic lobe. Development 137, 2981-2987. doi: 10.1242/dev.051250

Eid, T., Lee, T. S. W., Patrylo, P., and Zaveri, H. P. (2019). Astrocytes and glutamine synthetase in epileptogenesis. J. Neurosci. Res. 97, 1345-1362. doi: 10.1002/jnr. 24267

Eisen, J. S., and Melancon, E. (2001). Interactions with identified muscle cells break motoneuron equivalence in embryonic zebrafish. Nat. Neurosci. 4, 1065-1070. doi: $10.1038 / \mathrm{nn} 742$

Elmore, S. (2007). Apoptosis: a review of programmed cell death. Toxicol. Pathol. 35, 495-516. doi: 10.1080/01926230701320337

Enes, J., Haburcák, M., Sona, S., Gerard, N., Mitchell, A. C., Fu, W., et al. (2020). Satellite glial cells modulate cholinergic transmission between sympathetic neurons. PLoS One 15:e0218643. doi: 10.1371/journal.pone.0218643

Etxeberria, A., Hokanson, K. C., Dao, D. Q., Mayoral, S. R., Mei, F., Redmond, S. A., et al. (2016). Dynamic modulation of myelination in response to visual stimuli alters optic nerve conduction velocity. J. Neurosci. 36, 6937-6948. doi: 10.1523/JNEUROSCI.0908-16

Evans, T. A., and Bashaw, G. J. (2010). Axon guidance at the midline: of mice and flies. Curr. Opin. Neurobiol. 20, 79-85. doi: 10.1016/j.conb.2009.12.006

Falk, S., and Götz, M. (2017). Glial control of neurogenesis. Curr. Opin. Neurobiol. 47, 188-195. doi: 10.1016/j.conb.2017.10.025

Farhy-Tselnicker, I., and Allen, N. J. (2018). Astrocytes, neurons, synapses: a tripartite view on cortical circuit development. Neural Dev. 13:7. doi: 10.1186/ s13064-018-0104-y

Fatatis, A., and Russell, J. T. (1992). Spontaneous changes in intracellular calcium concentration in type I astrocytes from rat cerebral cortex in primary culture. Glia 5, 95-104. doi: 10.1002/glia.440050203

Featherstone, D. E. (2011). Glial solute carrier transporters in Drosophila and mice. Glia 59, 1351-1363. doi: 10.1002/glia.21085

Fernandes, V. M., Chen, Z., Rossi, A. M., Zipfel, J., and Desplan, C. (2017). Glia relay differentiation cues to coordinate neuronal development in Drosophila. Science 357, 886-891. doi: 10.1126/science.aan3174

Ferreira, L. S. S., Fernandes, C. S., Vieira, M. N. N., and De Felice, F. G. (2018). Insulin resistance in Alzheimer's disease. Front. Neurosci. 12:830. doi: 10.3389/ fnins.2018.00830

Ferrer, I., Bernet, E., Soriano, E., Del Rio, T., and Fonseca, M. (1990). Naturally occurring cell death in the cerebral cortex of the rat and removal of dead cells by transitory phagocytes. Neuroscience 39, 451-458. doi: 10.1016/0306-4522(90) 90281-8

Ferrón, S. R., Charalambous, M., Radford, E., McEwen, K., Wildner, H., Hind, E., et al. (2011). Postnatal loss of Dlk1 imprinting in stem cells and niche astrocytes regulates neurogenesis. Nature 475, 381-387. doi: 10.1038/nature10229

Filipello, F., Morini, R., Corradini, I., Zerbi, V., Canzi, A., Michalski, B., et al. (2018). The microglial innate immune receptor TREM2 is required for synapse elimination and normal brain connectivity. Immunity 48, 979-991.e8. doi: 10 . 1016/j.immuni.2018.04.016

Filipi, T., Hermanova, Z., Tureckova, J., Vanatko, O., and Anderova, M. (2020). Glial cells - The strategic targets in amyotrophic lateral sclerosis treatment. J. Clin. Med. 9:261. doi: 10.3390/jcm9010261

Fontenas, L., and Kucenas, S. (2017). Livin' On The Edge: glia shape nervous system transition zones. Curr. Opin. Neurobiol. 47, 44-51. doi: 10.1016/j.conb.2017. 09.008

Fontenas, L., and Kucenas, S. (2018). Motor exit point (MEP) glia: novel myelinating glia that bridge CNS and PNS myelin. Front. Cell. Neurosci. 12:333. doi: 10.3389/fncel.2018.00333

Fontenas, L., Welsh, T. G., Piller, M., Coughenour, P., Gandhi, A. V., Prober, D. A., et al. (2019). The neuromodulator adenosine regulates oligodendrocyte migration at motor exit point transition zones. Cell Rep. 27, 115-128.e5. doi: 10.1016/j.celrep.2019.03.013
Foster, A. Y., Bujalka, H., and Emery, B. (2019). Axoglial interactions in myelin plasticity: evaluating the relationship between neuronal activity and oligodendrocyte dynamics. Glia 67, 2038-2049. doi: 10.1002/glia.23629

Frade, J. M., and Barde, Y. A. (1998). Microglia-derived nerve growth factor causes cell death in the developing retina. Neuron 20, 35-41. doi: 10.1016/S08966273(00)80432-8

Franklin, R. J. M., and Blakemore, W. F. (1993). Requirements for schwann cell migration within cns environments: a viewpoint. Int. J. Dev. Neurosci. 11, 641-649. doi: 10.1016/0736-5748(93)90052-f

Freeman, M. R., Delrow, J., Kim, J., Johnson, E., and Doe, C. Q. (2003). Unwrapping glial biology: Gcm target genes regulating glial development, diversification, and function. Neuron 38, 567-580. doi: 10.1016/S0896-6273(03) 00289-7

Freeman, M. R., and Doherty, J. (2006). Glial cell biology in Drosophila and vertebrates. Trends Neurosci. 29, 82-90. doi: 10.1016/j.tins.2005.12.002

Friocourt, G., Liu, J. S., Antypa, M., Rakić, S., Walsh, C. A., and Parnavelas, J. G. (2007). Both doublecortin and doublecortin-like kinase play a role in cortical interneuron migration. J. Neurosci. 27, 3875-3883. doi: 10.1523/JNEUROSCI. 4530-06.2007

Fröb, F., Bremer, M., Finzsch, M., Kichko, T., Reeh, P., Tamm, E. R., et al. (2012). Establishment of myelinating schwann cells and barrier integrity between central and peripheral nervous systems depend on Sox10. Glia 60, 806-819. doi: 10.1002/glia.22310

Frölich, L., Blum-Degen, D., Riederer, P., and Hoyer, S. (1999). A disturbance in the neuronal insulin receptor signal transduction in sporadic Alzheimer's disease. Ann. N. Y. Acad. Sci. 893, 290-293. doi: 10.1111/j.1749-6632.1999.tb 07839.x

Frotscher, M. (1998). Cajal-Retzius cells, Reelin, and the formation of layers. Curr. Opin. Neurobiol. 8, 570-575. doi: 10.1016/S0959-4388(98)80082-2

Fuentes-Medel, Y., Ashley, J., Barria, R., Maloney, R., Freeman, M., and Budnik, V. (2012). Integration of a retrograde signal during synapse formation by glia-secreted TGF- $\beta$ ligand. Curr. Biol. 22, 1831-1838. doi: 10.1016/j.cub.2012. 07.063

Fuentes-Medel, Y., Logan, M. A., Ashley, J., Ataman, B., Budnik, V., and Freeman, M. R. (2009). Glia and muscle sculpt neuromuscular arbors by engulfing destabilized synaptic boutons and shed presynaptic debris. PLoS Biol. 7:e1000184. doi: 10.1371/journal.pbio.1000184

Fünfschilling, U., Supplie, L. M., Mahad, D., Boretius, S., Saab, A. S., Edgar, J., et al. (2012). Glycolytic oligodendrocytes maintain myelin and long-term axonal integrity. Nature 485, 517-521. doi: 10.1038/nature11007

Galloway, D. A., Phillips, A. E. M., Owen, D. R. J., and Moore, C. S. (2019). Phagocytosis in the brain: homeostasis and disease. Front. Immunol. 10:790. doi: 10.3389/fimmu.2019.00790

Gambello, M. J., Darling, D. L., Yingling, J., Tanaka, T., Gleeson, J. G., and Wynshaw-Boris, A. (2003). Multiple dose-dependent effects of Lis1 on cerebral cortical development. J. Neurosci. 23, 1719-1729. doi: 10.1523/jneurosci.23-0501719.2003

Gamsiz, E. D., Sciarra, L. N., Maguire, A. M., Pescosolido, M. F., van Dyck, L. I., and Morrow, E. M. (2015). Discovery of rare mutations in Autism: elucidating neurodevelopmental mechanisms. Neurotherapeutics 12, 553-571. doi: 10.1007/ s13311-015-0363-9

Gholizadeh, S., Halder, S. K., and Hampson, D. R. (2015). Expression of fragile $\mathrm{X}$ mental retardation protein in neurons and glia of the developing and adult mouse brain. Brain Res. 1596, 22-30. doi: 10.1016/j.brainres.2014.11.023

Ghosh, H. S. (2019). Adult neurogenesis and the promise of adult neural stem cells. J. Exp. Neurosci. 13:1179069519856876. doi: 10.1177/11790695198 56876

Gibson, E. M., Purger, D., Mount, C. W., Goldstein, A. K., Lin, G. L., Wood, L. S., et al. (2014). Neuronal activity promotes oligodendrogenesis and adaptive myelination in the mammalian brain. Science 344, 1252304. doi: 10.1126/ science. 1252304

Glass, C. K., Saijo, K., Winner, B., Marchetto, M. C., and Gage, F. H. (2010). Mechanisms underlying inflammation in neurodegeneration. Cell 140, 918 934. doi: 10.1016/j.cell.2010.02.016

Golding, J. P., and Cohen, J. (1997). Border controls at the mammalian spinal cord: late-surviving neural crest boundary cap cells at dorsal root entry sites may regulate sensory afferent ingrowth and entry zone morphogenesis. Mol. Cell. Neurosci. 9, 381-396. doi: 10.1006/mcne.1997.0647 
Götz, M., Nakafuku, M., and Petrik, D. (2016). Neurogenesis in the developing and adult brain-similarities and key differences. Cold Spring Harb. Perspect. Biol. 8:a018853. doi: $10.1101 /$ cshperspect.a018853

Grandgeorge, M., Lemonnier, E., and Jallot, N. (2013). Autism spectrum disorders: head circumference and body length at birth are both relative. Acta Paediatr. Int. J. Paediatr. 102, 901-907. doi: 10.1111/apa.12264

Green, L. A., Nebiolo, J. C., and Smithid, C. J. (2019). Microglia exit the CNS in spinal root avulsion. PLoS Biol. 17:e3000159. doi: 10.1371/journal.pbio.3000159

Gupta, S., Yadav, K., Mantri, S. S., Singhal, N. K., Ganesh, S., and Sandhir, R. (2018). Evidence for compromised insulin signaling and neuronal vulnerability in experimental model of sporadic Alzheimer's disease. Mol. Neurobiol. 55, 8916-8935. doi: 10.1007/s12035-018-0985-0

Guttenplan, K. A., Weigel, M. K., Adler, D. I., Couthouis, J., Liddelow, S. A., Gitler, A. D., et al. (2020). Knockout of reactive astrocyte activating factors slows disease progression in an ALS mouse model. Nat. Commun. 11:3753. doi: 10.1038/s41467-020-17514-9

Haidet-Phillips, A. M., Hester, M. E., Miranda, C. J., Meyer, K., Braun, L., Frakes, A., et al. (2011). Astrocytes from familial and sporadic ALS patients are toxic to motor neurons. Nat. Biotechnol. 29, 824-828. doi: 10.1038/nbt.1957

Hambardzumyan, D., Gutmann, D. H., and Kettenmann, H. (2016). The role of microglia and macrophages in glioma maintenance and progression. Nat. Neurosci. 19, 20-27. doi: 10.1038/nn.4185

Hamburger, V., and Oppenheim, R. W. (1982). Naturally occurring neuronal death in vertebrates. Neurosci. Comment. 1, 39-55. doi: 10.1007/978-1-48996743-5_7

Hamilton, N., Rutherford, H. A., Petts, J. J., Isles, H. M., Weber, T., Henneke, M., et al. (2020). The failure of microglia to digest developmental apoptotic cells contributes to the pathology of RNASET2-deficient leukoencephalopathy. Glia 68, 1531-1545. doi: 10.1002/glia.23829

Hammond, T. R., Robinton, D., and Stevens, B. (2018). Microglia and the brain: complementary partners in development and disease. Annu. Rev. Cell Dev. Biol. 34, 523-544. doi: 10.1146/annurev-cellbio-100616-060509

Herrera, A. A., Qiang, H., and Ko, C. P. (2000). The role of perisynaptic Schwann cells in development of neuromuscular junctions in the frog (Xenopus laevis). J. Neurobiol. 45, 237-254.

Hickman, S., Izzy, S., Sen, P., Morsett, L., and El Khoury, J. (2018). Microglia in neurodegeneration. Nat. Neurosci. 21, 1359-1369. doi: 10.1038/s41593-018$0242-\mathrm{x}$

Hidalgo, A. (2003). Neuron-glia interactions during axon guidance in Drosophila. Biochem. Soc. Trans. 31, 50-55. doi: 10.1042/bst0310050

Hidalgo, A., and Booth, G. E. (2000). Glia dictate pioneer axon trajectories in the Drosophila embryonic CNS. Development 127, 393-402.

Hidalgo, A., Urban, J., and Brand, A. H. (1995). Targeted ablation of glia disrupts axon tract formation in the Drosophila CNS. Development 121, 3703-3712.

Hill, S. A., Blaeser, A. S., Coley, A. A., Xie, Y., Shepard, K. A., Harwell, C. C., et al. (2019). Sonic hedgehog signaling in astrocytes mediates cell type-specific synaptic organization. eLife 8:e45545. doi: 10.7554/elife.45545

Hilu-Dadia, R., Hakim-Mishnaevski, K., Levy-Adam, F., and Kurant, E. (2018). Draper-mediated JNK signaling is required for glial phagocytosis of apoptotic neurons during Drosophila metamorphosis. Glia 66, 1520-1532. doi: 10.1002/ glia. 23322

Hines, J. H., Ravanelli, A. M., Schwindt, R., Scott, E. K., and Appel, B. (2015). Neuronal activity biases axon selection for myelination in vivo. Nat. Neurosci. 18, 683-689. doi: 10.1038/nn.3992

Ho, M. S. (2019). Microglia in Parkinson's disease. Adv. Exp. Med. Biol. 1175, 335-353. doi: 10.1007/978-981-13-9913-8_13

Holguera, I., and Desplan, C. (2018). Neuronal specification in space and time. Science 362, 176-180. doi: 10.1126/science.aas 9435

Homem, C. C. F., and Knoblich, J. A. (2012). Drosophila neuroblasts: a model for stem cell biology. Development 139, 4297-4310. doi: 10.1242/dev.080515

Hong, S., Beja-Glasser, V. F., Nfonoyim, B. M., Frouin, A., Li, S., Ramakrishnan, S., et al. (2016). Complement and microglia mediate early synapse loss in Alzheimer mouse models. Science 352, 712-716. doi: 10.1126/science.aad8373

Howard, L. J., Brown, H. E., Wadsworth, B. C., and Evans, T. A. (2019). Midline axon guidance in the Drosophila embryonic central nervous system. Semin. Cell Dev. Biol. 85, 13-25. doi: 10.1016/j.semcdb.2017.11.029

Howland, D. S., Liu, J., She, Y., Goad, B., Maragakis, N. J., Kim, B., et al. (2002). Focal loss of the glutamate transporter EAAT2 in a transgenic rat model of
SOD1 mutant-mediated amyotrophic lateral sclerosis (ALS). Proc. Natl. Acad. Sci. U.S.A. 99, 1604-1609. doi: 10.1073/pnas.032539299

Huang, T., Cui, J., Li, L., Hitchcock, P. F., and Li, Y. (2012). The role of microglia in the neurogenesis of zebrafish retina. Biochem. Biophys. Res. Commun. 421, 214-220. doi: 10.1016/j.bbrc.2012.03.139

Hughes, A. N., and Appel, B. (2019). Oligodendrocytes express synaptic proteins that modulate myelin sheath formation. Nat. Commun. 10:4125. doi: 10.1038/ s41467-019-12059-y

Iram, T., Ramirez-Ortiz, Z., Byrne, M. H., Coleman, U. A., Kingery, N. D., Means, T. K., et al. (2016). Megf10 Is a receptor for C1Q that mediates clearance of apoptotic cells by astrocytes. J. Neurosci. 36, 5185-5192. doi: 10.1523/ JNEUROSCI.3850-15.2016

Jablonka-Shariff, A., Lu, C. Y., Campbell, K., Monk, K. R., and Snyder-Warwick, A. K. (2020). Gpr126/Adgrg6 contributes to the terminal Schwann cell response at the neuromuscular junction following peripheral nerve injury. Glia 68 , 1182-1200. doi: 10.1002/glia.23769

Jacobs, J. R. (2000). The Midline Glia of Drosophila: a molecular genetic model for the developmental functions of Glia. Prog. Neurobiol. 62, 475-508. doi: 10.1016/S0301-0082(00)00016-2

Jafferali, S., Dumont, Y., Sotty, F., Robitaille, Y., Quirion, R., and Kar, S. (2000). Insulin-like growth factor-I and its receptor in the frontal cortex, hippocampus, and cerebellum of normal human and Alzheimer disease brains. Synapse 38, 450-459.

Jamuar, S. S., and Walsh, C. A. (2015). Genomic variants and variations in malformations of cortical development. Pediatr. Clin. North Am. 62, 571-585. doi: 10.1016/j.pcl.2015.03.002

Jessen, K. R., and Mirsky, R. (2016). The repair Schwann cell and its function in regenerating nerves. J. Physiol. 594, 3521-3531. doi: 10.1113/JP270874

John Lin, C. C., Yu, K., Hatcher, A., Huang, T. W., Lee, H. K., Carlson, J., et al. (2017). Identification of diverse astrocyte populations and their malignant analogs. Nat. Neurosci. 20, 396-405. doi: 10.1038/nn.4493

Jung, J. H., Smith, I., and Mikesh, M. (2019). Terminal Schwann cell and vacant site mediated synapse elimination at developing neuromuscular junctions. Sci. Rep. 9:18594. doi: 10.1038/s41598-019-55017-w

Kaiser, M., Maletzki, I., Hülsmann, S., Holtmann, B., Schulz-Schaeffer, W., Kirchhoff, F., et al. (2006). Progressive loss of a glial potassium channel (KCNJ10) in the spinal cord of the SOD1 (G93A) transgenic mouse model of amyotrophic lateral sclerosis. J. Neurochem. 99, 900-912. doi: 10.1111/j.14714159.2006.04131.x

Kalsi, A. S., Greenwood, K., Wilkin, G., and Butt, A. M. (2004). Kir4.1 expression by astrocytes and oligodendrocytes in CNS white matter: a developmental study in the rat optic nerve. J. Anat. 204, 475-485. doi: 10.1111/j.0021-8782.2004. 00288.x

Kamitaki, N., Sekar, A., Handsaker, R. E., de Rivera, H., Tooley, K., Morris, D. L., et al. (2020). Complement genes contribute sex-biased vulnerability in diverse disorders. Nature 582, 577-581. doi: 10.1038/s41586-020-2277-x

Kanai, M. I., Kim, M. J., Akiyama, T., Takemura, M., Wharton, K., O’Connor, M. B., et al. (2018). Regulation of neuroblast proliferation by surface glia in the Drosophila larval brain. Sci. Rep. 8:3730. doi: 10.1038/s41598-018-22028-y

Kang, H., Tian, L., Mikesh, M., Lichtman, J. W., and Thompson, W. J. (2014). Terminal Schwann cells participate in neuromuscular synapse remodeling during reinnervation following nerve injury. J. Neurosci. 34, 6323-6333. doi: 10.1523/JNEUROSCI.4673-13.2014

Kang, H., Tian, L., and Thompson, W. (2003). Terminal Schwann cells guide the reinnervation of muscle after nerve injury. J. Neurocytol. 32, 975-985. doi: 10.1023/B:NEUR.0000020636.27222.2d

Kang, H., Tian, L., and Thompson, W. J. (2019). Schwann cell guidance of nerve growth between synaptic sites explains changes in the pattern of muscle innervation and remodeling of synaptic sites following peripheral nerve injuries. J. Comp. Neurol. 527, 1388-1400. doi: 10.1002/cne.24625

Kang, S. H., Li, Y., Fukaya, M., Lorenzini, I., Cleveland, D. W., Ostrow, L. W., et al. (2013). Degeneration and impaired regeneration of gray matter oligodendrocytes in amyotrophic lateral sclerosis. Nat. Neurosci. 16, 571-579. doi: 10.1038/nn.3357

Kappeler, C., Dhenain, M., Phan Dinh Tuy, F., Saillour, Y., Marty, S., Fallet-Bianco, C., et al. (2007). Magnetic resonance imaging and histological studies of corpus callosal and hippocampal abnormalities linked to doublecortin deficiency. J. Comp. Neurol. 500, 239-254. doi: 10.1002/cne.21170 
Kappeler, C., Saillour, Y., Baudoin, J. P., Tuy, F. P. D., Alvarez, C., Houbron, C., et al. (2006). Branching and nucleokinesis defects in migrating interneurons derived from doublecortin knockout mice. Hum. Mol. Genet. 15, 1387-1400. doi: 10.1093/hmg/ddl062

Katz, M., Corson, F., Keil, W., Singhal, A., Bae, A., Lu, Y., et al. (2019). Glutamate spillover in $C$. elegans triggers repetitive behavior through presynaptic activation of MGL-2/mGluR5. Nat. Commun. 10:1882. doi: 10.1038/s41467019-09581-4

Khakh, B. S., and Sofroniew, M. V. (2015). Diversity of astrocyte functions and phenotypes in neural circuits. Nat. Neurosci. 18, 942-952. doi: 10.1038/nn.4043

Klämbt, C. (2009). Modes and regulation of glial migration in vertebrates and invertebrates. Nat. Rev. Neurosci. 10, 769-779. doi: 10.1038/nrn2720

Klämbt, C., Jacobs, J. R., and Goodman, C. S. (1991). The midline of the drosophila central nervous system: a model for the genetic analysis of cell fate, cell migration, and growth cone guidance. Cell 64, 801-815. doi: 10.1016/00928674(91)90509-W

Kornbluth, S., and White, K. (2005). Apoptosis in Drosophila: Neither fish nor fowl (nor man, nor worm). J. Cell Sci. 118, 1779-1787. doi: 10.1242/jcs.02377

Kremer, M. C., Jung, C., Batelli, S., Rubin, G. M., and Gaul, U. (2017). The glia of the adult Drosophila nervous system. Glia 65, 606-638. doi: 10.1002/glia.23115

Kriegstein, A., and Alvarez-Buylla, A. (2009). The glial nature of embryonic and adult neural stem cells. Annu. Rev. Neurosci. 32, 149-184. doi: 10.1146/annurev. neuro.051508.135600

Kroehne, V., Freudenreich, D., Hans, S., Kaslin, J., and Brand, M. (2011). Regeneration of the adult zebrafish brain from neurogenic radial glia-type progenitors. Development 138, 4831-4841. doi: 10.1242/dev.072587

Kucenas, S. (2015). Perineurial Glia. Cold Spring Harb. Lab. Press 7:a020511.

Kucenas, S., Wang, W.-D., Knapik, E. W., and Appel, B. (2009). A selective glial barrier at motor axon exit points prevents oligodendrocyte migration from the spinal cord. J. Neurosci. 29, 15187-15194. doi: 10.1523/JNEUROSCI.4193-09. 2009

Kucenas, S., Takada, N., Park, H. C., Woodruff, E., Broadie, K., and Appel, B. (2008). CNS-derived glia ensheath peripheral nerves and mediate motor root development. Nat. Neurosci. 11, 143-151. doi: 10.1038/nn2025

Kucheryavykh, Y. V., Kucheryavykh, L. Y., Nichols, C. G., Maldonado, H. M., Baksi, K., Reichenbach, A., et al. (2007). Downregulation of Kir4.1 inward rectifying potassium channel subunits by RNAi impairs potassium transfer and glutamate uptake by cultured cortical astrocytes. Glia 55, 274-281. doi: 10.1002/glia.20455

Kurant, E. (2011). Keeping the CNS clear: glial phagocytic functions in Drosophila. Glia 59, 1304-1311. doi: 10.1002/glia.21098

Kurant, E., Axelrod, S., Leaman, D., and Gaul, U. (2008). Six-microns-under acts upstream of draper in the Glial phagocytosis of apoptotic neurons. Cell 133, 498-509. doi: 10.1016/j.cell.2008.02.052

Kwon, H. J., Ma, S., and Huang, Z. (2011). Radial glia regulate Cajal-Retzius cell positioning in the early embryonic cerebral cortex. Dev. Biol. 351, 25-34. doi: 10.1016/j.ydbio.2010.12.026

Kyritsis, N., Kizil, C., Zocher, S., Kroehne, V., Kaslin, J., Freudenreich, D., et al. (2012). Acute inflammation initiates the regenerative response in the adult zebrafish brain. Science 338, 1353-1356. doi: 10.1126/science.1228773

Lainhart, J. E., Bigler, E. D., Bocian, M., Coon, H., Dinh, E., Dawson, G., et al. (2006). Head circumference and height in Autism. Am. J. Med. Genet. A 140, 2257-2274. doi: 10.1002/ajmg.a.31465

Larson, V. A., Mironova, Y., Vanderpool, K. G., Waisman, A., Rash, J. E., Agarwal, A., et al. (2018). Oligodendrocytes control potassium accumulation in white matter and seizure susceptibility. eLife 7:e34829. doi: 10.7554/eLife.34829

Learte, A. R., and Hidalgo, A. (2007). The role of glial cells in axon guidance, fasciculation and targeting. Adv. Exp. Med. Biol. 621, 156-166. doi: 10.1007/ 978-0-387-76715-4_12

Lee, F. H. F., Lai, T. K. Y., Su, P., and Liu, F. (2019). Altered cortical Cytoarchitecture in the Fmrl knockout mouse. Mol. Brain 12:56.

Lee, Y., Morrison, B. M., Li, Y., Lengacher, S., Farah, M. H., Hoffman, P. N., et al. (2012). Oligodendroglia metabolically support axons and contribute to neurodegeneration. Nature 487, 443-448. doi: 10.1038/nature11314

Lee, Y. M., and Sun, Y. H. (2015). Drosophila as a model to study the role of glia in neurodegeneration. J. Neurogenet. 29, 69-79. doi: 10.3109/01677063.2015. 1076816
Lehrman, E. K., Wilton, D. K., Litvina, E. Y., Welsh, C. A., Chang, S. T., Frouin, A., et al. (2018). CD47 protects synapses from excess microglia-mediated pruning during development. Neuron 100, 120-134.e6. doi: 10.1016/j.neuron.2018. 09.017

Leiserson, W. M., Forbush, B., and Keshishian, H. (2011). Drosophila glia use a conserved cotransporter mechanism to regulate extracellular volume. Glia 59, 320-332. doi: 10.1002/glia.21103

Leiserson, W. M., Harkins, E. W., and Keshishian, H. (2000). Fray, a Drosophila serine/threonine kinase homologous to mammalian PASK, is required for axonal ensheathment. Neuron 28, 793-806. doi: 10.1016/S0896-6273(00) 00154-9

Leiserson, W. M., and Keshishian, H. (2011). Maintenance and regulation of extracellular volume and the ion environment in Drosophila larval nerves. Glia 59, 1312-1321. doi: 10.1002/glia.21132

Lemke, G. (2001). Glial control of neuronal development. Annu. Rev. Neurosci. 24, 87-105. doi: 10.1146/annurev.neuro.24.1.87

Lepore, A. C., Rauck, B., Dejea, C., Pardo, A. C., Rao, M. S., Rothstein, J. D., et al. (2008). Focal transplantation-based astrocyte replacement is neuroprotective in a model of motor neuron disease. Nat. Neurosci. 11, 1294-1301. doi: 10.1038/ nn. 2210

Lewis, G. M., and Kucenas, S. (2014). Perineurial glia are essential for motor axon regrowth following nerve injury. J. Neurosci. 34, 12762-12777. doi: 10.1523/JNEUROSCI.1906-14.2014

Li, H., Shuster, S. A., Li, J., and Luo, L. (2018). Linking neuronal lineage and wiring specificity. Neural Dev. 13:5. doi: 10.1186/s13064-018-0102-0

Li, J. (2015). Molecular regulators of nerve conduction - Lessons from inherited neuropathies and rodent genetic models. Exp. Neurol. 267, 209-218. doi: 10. 1016/j.expneurol.2015.03.009

Li, S., Jin, Z., Koirala, S., Bu, L., Xu, L., Hynes, R. O., et al. (2008). GPR56 regulates pial basement membrane integrity and cortical lamination. J. Neurosci. 28, 5817-5826. doi: 10.1523/JNEUROSCI.0853-08.2008

Licht, T., and Keshet, E. (2015). The vascular niche in adult neurogenesis. Mech. Dev. 138, 56-62. doi: 10.1016/j.mod.2015.06.001

Liddelow, S. A., and Barres, B. A. (2017). Reactive astrocytes: production, function, and therapeutic potential. Immunity 46, 957-967. doi: 10.1016/j.immuni.2017. 06.006

Liddelow, S. A., Guttenplan, K. A., Clarke, L. E., Bennett, F. C., Bohlen, C. J., Schirmer, L., et al. (2017). Neurotoxic reactive astrocytes are induced by activated microglia. Nature 541, 481-487. doi: 10.1038/nature21029

Lie, D. C., Colamarino, S. A., Song, H. J., Désiré, L., Mira, H., Consiglio, A., et al. (2005). Wnt signalling regulates adult hippocampal neurogenesis. Nature 437, 1370-1375. doi: 10.1038/nature04108

Lino, M. M., Schneider, C., and Caroni, P. (2002). Accumulation of SOD1 mutants in postnatal motoneurons does not cause motoneuron pathology or motoneuron disease. J. Neurosci. 22, 4825-4832. doi: 10.1523/jneurosci.22-1204825.2002

Lioy, D. T., Garg, S. K., Monaghan, C. E., Raber, J., Foust, K. D., Kaspar, B. K., et al. (2011). A role for glia in the progression of Rett-syndrome. Nature 475, 497-500. doi: 10.1038/nature10214

Liston, C., Cichon, J. M., Jeanneteau, F., Jia, Z., Chao, M. V., and Gan, W.B. (2013). Circadian glucocorticoid oscillations promote learning-dependent synapse formation and maintenance. Nat. Neurosci. 16, 698-705. doi: 10.1038/ nn.3387

Littlejohn, E. L., Scott, D., and Saatman, K. E. (2020). Insulin-like growth factor-1 overexpression increases long-term survival of posttrauma- born hippocampal neurons while inhibiting ectopic migration following traumatic brain injury. Acta Neuropathol. Commun. 8:46. doi: 10.1186/s40478-020-00925-6

Long, P., Wan, G., Roberts, M. T., and Corfas, G. (2018). Myelin development, plasticity, and pathology in the auditory system. Dev. Neurobiol. 78, 80-92. doi: $10.1002 /$ dneu.22538

Love, F. M., and Thompson, W. J. (1998). Schwann cells proliferate at rat neuromuscular junctions during development and regeneration. J. Neurosci. 18, 9376-9385. doi: 10.1523/jneurosci.18-22-09376.1998

Lutz, A. B., Chung, W. S., Sloan, S. A., Carson, G. A., Zhou, L., Lovelett, E., et al. (2017). Schwann cells use TAM receptor-mediated phagocytosis in addition to autophagy to clear myelin in a mouse model of nerve injury. Proc. Natl. Acad. Sci. U.S.A. 114, E8072-E8080. doi: 10.1073/pnas.1710566114 
Lutz, S. E., Zhao, Y., Gulinello, M., Lee, S. C., Raine, C. S., and Brosnan, C. F. (2009). Deletion of astrocyte connexins 43 and 30 leads to a dysmyelinating phenotype and hippocampal CA1 vacuolation. J. Neurosci. 29, 7743-7752. doi: 10.1523/JNEUROSCI.0341-09.2009

Lyons, D. A., and Talbot, W. S. (2015). Glial cell development and function in zebrafish. Cold Spring Harb. Perspect. Biol. 7:a020586. doi: 10.1101/cshperspect. a020586

Ma, Z., Stork, T., Bergles, D. E., and Freeman, M. R. (2016). Neuromodulators signal through astrocytes to alter neural circuit activity and behaviour. Nature 539, 428-432. doi: 10.1038/nature20145

MacDonald, J. M., Beach, M. G., Porpiglia, E., Sheehan, A. E., Watts, R. J., and Freeman, M. R. (2006). The Drosophila cell corpse engulfment receptor Draper mediates glial clearance of severed axons. Neuron 50, 869-881. doi: 10.1016/j. neuron.2006.04.028

Maghsoudi, N., Zakeri, Z., and Lockshin, R. A. (2012). Programmed cell death and apoptosis - Where it came from and where it is going: from Elie Metchnikoff to the control of caspases. Exp. Oncol. 34, 146-152.

Maier, S. F. (1984). Learned helplessness and animal models of depression. Prog. Neuropsychopharmacol. Biol. Psychiatry 8, 435-446.

Malatesta, P., and Götz, M. (2013). Radial glia - From boring cables to stem cell stars. Development 140, 483-486. doi: 10.1242/dev.085852

Malatesta, P., Hartfuss, E., and Götz, M. (2000). Isolation of radial glial cells by fluorescent-activated cell sorting reveals a neural lineage. Development 127, 5253-5263.

Mangia, S., Simpson, I. A., Vannucci, S. J., and Carruthers, A. (2009). The in vivo neuron-to-astrocyte lactate shuttle in human brain: evidence from modeling of measured lactate levels during visual stimulation. J. Neurochem. 109, 55-62. doi: 10.1111/j.1471-4159.2009.06003.x

Marcorelles, P., Laquerrière, A., Adde-Michel, C., Marret, S., Saugier-Veber, P., Beldjord, C., et al. (2010). Evidence for tangential migration disturbances in human lissencephaly resulting from a defect in LIS1, DCX and ARX genes. Acta Neuropathol. 120, 503-515. doi: 10.1007/s00401-010-0692-z

Marín, O., and Rubenstein, J. L. R. (2003). Cell migration in the forebrain. Annu. Rev. Neurosci. 26, 441-483. doi: 10.1146/annurev.neuro.26.041002.131058

Marinelli, S., Basilico, B., Marrone, M. C., and Ragozzino, D. (2019). Microglianeuron crosstalk: signaling mechanism and control of synaptic transmission. Semin. Cell Dev. Biol. 94, 138-151. doi: 10.1016/j.semcdb.2019.05.017

Marín-Teva, J. L., Dusart, I., Colin, C., Gervais, A., Van Rooijen, N., and Mallat, M. (2004). Microglia promote the death of developing Purkinje cells. Neuron 41, 535-547. doi: 10.1016/S0896-6273(04)00069-8

Marshall-Phelps, K. L. H., Kegel, L., Baraban, M., Ruhwedel, T., Almeida, R. G., Rubio-Brotons, M., et al. (2020). Neuronal activity disrupts myelinated axon integrity in the absence of NKCC1b. J. Cell Biol. 219:e201909022. doi: 10.1083/ JCB.201909022

Mason, C. A., and Sretavan, D. W. (1997). Glia, neurons, and axon pathfinding during optic chiasm development. Curr. Opin. Neurobiol. 7, 647-653. doi: 10. 1016/S0959-4388(97)80084-0

McCauley, M. E., and Baloh, R. H. (2019). Inflammation in ALS/FTD pathogenesis. Acta Neuropathol. 137, 715-730. doi: 10.1007/s00401-018-1933-9

McCombe, P. A., and Henderson, R. D. (2011). The role of immune and inflammatory mechanisms in ALS. Curr. Mol. Med. 11, 246-254. doi: 10.2174/ 156652411795243450

McKay, R. D. G. (1989). The origins of cellular diversity in the mammalian central nervous system. Cell 58, 815-821. doi: 10.1016/0092-8674(89)90934-3

McLaughlin, C. N., Perry-Richardson, J. J., Coutinho-Budd, J. C., and Broihier, H. T. (2019). Dying neurons utilize innate immune signaling to prime glia for phagocytosis during development. Dev. Cell 48, 506-522. doi: 10.1016/j.devcel. 2018.12.019

McManus, M. F., Nasrallah, I. M., Pancoast, M. M., Wynshaw-Boris, A., and Golden, J. A. (2004). Lis1 is necessary for normal non-radial migration of inhibitory interneurons. Am. J. Pathol. 165, 775-784. doi: 10.1016/S00029440(10)63340-8

Mederos, S., and Perea, G. (2019). GABAergic-astrocyte signaling: a refinement of inhibitory brain networks. Glia 67, 1842-1851. doi: 10.1002/glia.23644

Mensch, S., Baraban, M., Almeida, R., Czopka, T., Ausborn, J., El Manira, A., et al. (2015). Synaptic vesicle release regulates myelin sheath number of individual oligodendrocytes in vivo. Nat. Neurosci. 18, 628-630. doi: 10.1038/nn.3991
Michailov, G. V., Sereda, M. W., Brinkmann, B. G., Fischer, T. H., Haug, B., Birchmeier, C., et al. (2004). Axonal neuregulin-1 regulates myelin sheath thickness. Science 304, 700-703. doi: 10.1126/science.1095862

Minocha, S., Valloton, D., Ypsilanti, A. R., Fiumelli, H., Allen, E. A., Yanagawa, Y., et al. (2015). Nkx2.1-derived astrocytes and neurons together with Slit2 are indispensable for anterior commissure formation. Nat. Commun. 6:6887. doi: $10.1038 /$ ncomms7887

Miura, M. (2012). Apoptotic and nonapoptotic caspase functions in animal development. Cold Spring Harb. Perspect. Biol. 4:a008664. doi: 10.1101/ cshperspect.a008664

Miyamoto, A., Wake, H., Ishikawa, A. W., Eto, K., Shibata, K., Murakoshi, H., et al. (2016). Microglia contact induces synapse formation in developing somatosensory cortex. Nat. Commun. 7:12540. doi: 10.1038/ncomms 12540

Molofsky, A. V., Kelley, K. W., Tsai, H., Redmond, S. A., Chang, S. M., Madireddy, L., et al. (2014). Astrocyte-encoded positional cues maintain sensorimotor circuit integrity. Nature 509, 189-194. doi: 10.1038/nature13161.Astrocyteencoded

Moloney, A. M., Griffin, R. J., Timmons, S., O’Connor, R., Ravid, R., and O’Neill, C. (2010). Defects in IGF-1 receptor, insulin receptor and IRS-1/2 in Alzheimer's disease indicate possible resistance to IGF-1 and insulin signalling. Neurobiol. Aging 31, 224-243. doi: 10.1016/j.neurobiolaging.2008.04.002

Mondelli, V., Vernon, A. C., Turkheimer, F., Dazzan, P., and Pariante, C. M. (2017). Brain microglia in psychiatric disorders. Lancet Psychiatry 4, 563-572. doi: 10.1016/S2215-0366(17)30101-3

Monje, M. (2018). Myelin plasticity and nervous system function. Annu. Rev. Neurosci. 41, 61-76. doi: 10.1146/annurev-neuro-080317-061853

Moon, H. M., and Wynshaw-Boris, A. (2013). Cytoskeleton in action: lissencephaly, a neuronal migration disorder. Wiley Interdiscip Rev. Dev. Biol. 2, 229-245. doi: 10.1002/wdev.67

Morante, J., Vallejo, D. M., Desplan, C., and Dominguez, M. (2013). Conserved miR-8/miR-200 defines a glial niche that controls neuroepithelial expansion and neuroblast transition. Dev. Cell 27, 174-187. doi: 10.1016/j.devcel.2013.09.018

Moreno-Estellés, M., González-Gómez, P., Hortigüela, R., Díaz-Moreno, M., San Emeterio, J., Al, C., et al. (2012). Symmetric expansion of neural stem cells from the adult olfactory bulb is driven by astrocytes via WNT7A. Stem Cells 30, 2796-2809. doi: 10.1002/stem.1243

Morgan, S. C., Taylor, D. L., and Pocock, J. M. (2004). Microglia release activators of neuronal proliferation mediated by activation of mitogen-activated protein kinase, phosphatidylinositol-3-kinase/Akt and delta-Notch signalling cascades. J. Neurochem. 90, 89-101. doi: 10.1111/j.1471-4159.2004.02461.x

Morrison, B. M., Lee, Y., and Rothstein, J. D. (2013). Oligodendroglia: metabolic supporters of axons. Trends Cell Biol. 23, 644-651. doi: 10.1016/j.tcb.2013. 07.007

Morsch, M., Radford, R., Lee, A., Don, E. K., Badrock, A. P., Hall, T. E., et al. (2015). In vivo characterization of microglial engulfment of dying neurons in the zebrafish spinal cord. Front. Cell. Neurosci. 9:321. doi: 10.3389/fncel.2015.00321

Mu, Y., Bennett, D. V., Rubinov, M., Narayan, S., Yang, C. T., Tanimoto, M., et al. (2019). Glia accumulate evidence that actions are futile and suppress unsuccessful behavior. Cell 178, 27-43.e19. doi: 10.1016/j.cell.2019.05.050

Murphy-Royal, C., Dupuis, J., Groc, L., and Oliet, S. H. R. (2017). Astroglial glutamate transporters in the brain: regulating neurotransmitter homeostasis and synaptic transmission. J. Neurosci. Res. 95, 2140-2151. doi: 10.1002/jnr. 24029

Musashe, D. T., Purice, M. D., Speese, S. D., Doherty, J., and Logan, M. A. (2016). Insulin-like signaling promotes glial phagocytic clearance of degenerating axons through regulation of Draper. Cell Rep. 16, 1838-1850. doi: 10.1016/j. celrep.2016.07.022

Muthukumar, A. K., Stork, T., and Freeman, M. R. (2014). Activity-dependent regulation of astrocyte GAT levels during synaptogenesis. Nat. Neurosci. 17, 1340-1350. doi: 10.1038/nn.3791

Napoli, I., and Neumann, H. (2009). Microglial clearance function in health and disease. Neuroscience 158, 1030-1038. doi: 10.1016/j.neuroscience.2008.06.046

Nazareth, L., Lineburg, K. E., Chuah, M. I., Tello Velasquez, J., Chehrehasa, F., St John, J. A., et al. (2015). Olfactory ensheathing cells are the main phagocytic cells that remove axon debris during early development of the olfactory system. J. Comp. Neurol. 523, 479-494. doi: 10.1002/cne.23694 
Nemes-Baran, A. D., White, D. R., and DeSilva, T. M. (2020). Fractalkinedependent microglial pruning of viable oligodendrocyte progenitor cells regulates myelination. Cell Rep. 32:108047. doi: 10.1016/j.celrep.2020.108047

Neniskyte, U., and Gross, C. T. (2017). Errant gardeners: glial-cell-dependent synaptic pruning and neurodevelopmental disorders. Nat. Rev. Neurosci. 18, 658-670. doi: 10.1038/nrn.2017.110

Nett, W. J., Oloff, S. H., and McCarthy, K. D. (2002). Hippocampal astrocytes in situ exhibit calcium oscillations that occur independent of neuronal activity. J. Neurophysiol. 87, 528-537. doi: 10.1152/jn.00268.2001

Nguyen, P. T., Dorman, L. C., Pan, S., Vainchtein, I. D., Han, R. T., Nakao-Inoue, H., et al. (2020). Microglial remodeling of the extracellular matrix promotes synapse plasticity. Cell 182, 388-403.e15. doi: 10.1016/j.cell.2020.05.050

Niederländer, C., and Lumsden, A. (1996). Late emigrating neural crest cells migrate specifically to the exit points of cranial branchiomotor nerves. Development 122, 2367-2374.

Nimmerjahn, A., Mukamel, E. A., and Schnitzer, M. J. (2009). Motor behavior activates Bergmann glial networks. Neuron 62, 400-412. doi: 10.1016/j.neuron. 2009.03.019

Noctor, S. C., Flint, A. C., Weissman, T. A., Dammerman, R. S., and Kriegstein, A. R. (2001). Neurons derived from radial glial cells establish radial units in neocortex. Nature 409, 714-720. doi: 10.1038/35055553

Nwaobi, S. E., Cuddapah, V. A., Patterson, K. C., Randolph, A. C., and Olsen, M. L. (2016). The role of glial specific Kir4.1 in normal and pathological states of the CNS. Acta Neuropathol. 132, 1-21. doi: 10.1007/s00401-016-1553-1

Ohno, Y. (2018). Astrocytic Kir4.1 potassium channels as a novel therapeutic target for epilepsy and mood disorders. Neural Regen. Res. 13, 651-652. doi: 10.4103/1673-5374.230355

Olsen, M. L., Higashimori, H., Campbell, S. L., Hablitz, J. J., and Sontheimer, H. (2006). Functional expression of Kir4.1 channels in spinal cord astrocytes. Glia 53, 516-528. doi: 10.1002/glia.20312

Olsen, M. L., Khakh, B. S., Skatchkov, S. N., Zhou, M., Lee, C. J., and Rouach, N. (2015). New insights on astrocyte ion channels: critical for homeostasis and neuron-glia signaling. J. Neurosci. 35, 13827-13835. doi: 10.1523/JNEUROSCI. 2603-15.2015

Oppenheim, R. W. (1991). Cell death during development of the nervous system. Annu. Rev. Neurosci. 14, 453-501. doi: 10.1146/annurev.ne.14.030191.002321

Ortega, F., Gascón, S., Masserdotti, G., Deshpande, A., Simon, C., Fischer, J., et al. (2013). Oligodendrogliogenic and neurogenic adult subependymal zone neural stem cells constitute distinct lineages and exhibit differential responsiveness to Wnt signalling. Nat. Cell Biol. 15, 602-613. doi: 10.1038/ncb2736

Otsuki, L., and Brand, A. H. (2020). Quiescent neural stem cells for brain repair and regeneration: lessons from model systems. Trends Neurosci. 43, 213-226. doi: 10.1016/j.tins.2020.02.002

Pancoast, M., Dobyns, W., and Golden, J. A. (2005). Interneuron deficits in patients with the Miller-Dieker syndrome. Acta Neuropathol. 109, 400-404. doi: 10. 1007/s00401-004-0979-z

Paolicelli, R. C., Bolasco, G., Pagani, F., Maggi, L., Scianni, M., Panzanelli, P., et al. (2011). Synaptic pruning by microglia is necessary for normal brain development. Science 333, 1456-1458. doi: 10.1126/science.1202529

Parinejad, N., Peco, E., Ferreira, T., Stacey, S. M., and Van Meyel, D. J. (2016). Disruption of an EAAT-mediated chloride channel in a Drosophila model of ataxia. J. Neurosci. 36, 7640-7647. doi: 10.1523/JNEUROSCI.0197-16.2016

Parkhurst, C. N., Yang, G., Ninan, I., Savas, J. N., Yates, J. R., Lafaille, J. J., et al. (2013). Microglia promote learning-dependent synapse formation through brain-derived neurotrophic factor. Cell 155, 1596-1609. doi: 10.1016/j.cell.2013. 11.030

Paukert, M., Agarwal, A., Cha, J., Doze, V. A., Kang, J. U., and Bergles, D. E. (2014). Norepinephrine controls astroglial responsiveness to local circuit activity. Neuron 82, 1263-1270. doi: 10.1016/j.neuron.2014.04.038

Pellerin, L., and Magistretti, P. J. (1994). Glutamate uptake into astrocytes stimulates aerobic glycolysis: a mechanism coupling neuronal activity to glucose utilization. Proc. Natl. Acad. Sci. U.S.A. 91, 10625-10629. doi: 10.1073/pnas.91. 22.10625

Peng, J. J., Lin, S. H., Liu, Y. T., Lin, H. C., Li, T. N., and Yao, C. K. (2019). A circuitdependent ROS feedback loop mediates glutamate excitotoxicity to sculpt the Drosophila motor system. eLife 8:e47372. doi: 10.7554/eLife.47372

Peretto, P., Dati, C., De Marchis, S., Kim, H. H., Ukhanova, M., Fasolo, A., et al. (2004). Expression of the secreted factors noggin and bone morphogenetic proteins in the subependymal layer and olfactory bulb of the adult mouse brain. Neuroscience 128, 685-696. doi: 10.1016/j.neuroscience.2004.06.053

Pérez-Gómez, R., Slováková, J., Rives-Quinto, N., Krejci, A., and Carmena, A. (2013). A serrate-notch-canoe complex mediates essential interactions between glia and neuroepithelial cells during Drosophila optic lobe development. J. Cell Sci. 126, 4873-4884. doi: 10.1242/jcs.125617

Perlin, J. R., Lush, M. E., Stephens, W. Z., Piotrowski, T., and Talbot, W. S. (2011). Neuronal neuregulin 1 type III directs schwann cell migration. Development 138, 4639-4648. doi: 10.1242/dev.068072

Pettmann, B., and Henderson, C. E. (1998). Neuronal cell death. Neuron 20, 633-647. doi: 10.1016/S0896-6273(00)81004-1

Pfisterer, U., and Khodosevich, K. (2017). Neuronal survival in the brain: neuron type-specific mechanisms. Cell Death Dis. 8:e2643. doi: 10.1038/cddis.2017.64

Pfrieger, F. W., and Barres, B. A. (1997). Synaptic Efficacy Enhanced by Glial Cells in Vitro. 277, 1684-1687.

Phatnani, H., and Maniatis, T. (2015). Astrocytes in neurodegenerative disease. Cold Spring Harb. Perspect. Biol. 7:a020628. doi: 10.1101/cshperspect.a020628

Philips, T., and Rothstein, J. D. (2014). Glial cells in amyotrophic lateral sclerosis. Exp. Neurol. 262, 111-120. doi: 10.1016/j.expneurol.2014.05.015

Philips, T., and Rothstein, J. D. (2017). Oligodendroglia: metabolic supporters of neurons. J. Clin. Invest. 127, 3271-3280. doi: 10.1172/JCI90610

Pilaz, L. J., McMahon, J. J., Miller, E. E., Lennox, A. L., Suzuki, A., Salmon, E., et al. (2016). Prolonged mitosis of neural progenitors alters cell fate in the developing brain. Neuron 89, 83-99. doi: 10.1016/j.neuron.2015.12.007

Pinson, A., Namba, T., and Huttner, W. B. (2019). Malformations of human neocortex in development - Their progenitor cell basis and experimental model systems. Front. Cell. Neurosci. 13:305. doi: 10.3389/fncel.2019.00305

Placzek, M., and Briscoe, J. (2005). The floor plate: multiple cells, multiple signals. Nat. Rev. Neurosci. 6, 230-240. doi: 10.1038/nrn1628

Plazaola-Sasieta, H., Zhu, Q., Gaitán-Peñas, H., Rios, M., Estévez, R., and Morey, M. (2019). Drosophila ClC-a is required in glia of the stem cell niche for proper neurogenesis and wiring of neural circuits. Glia 67, 2374-2398. doi: 10.1002/ glia.23691

Poduslo, J. F., Curran, G. L., and Berg, C. T. (1994). Macromolecular permeability across the blood-nerve and blood-brain barriers. Proc. Natl. Acad. Sci. U.S.A. 91, 5705-5709. doi: 10.1073/pnas.91.12.5705

Poeck, B., Fischer, S., Gunning, D., Zipursky, S. L., and Salecker, I. (2001). Glial cells mediate target layer selection of retinal axons in the developing visual system of Drosophila. Neuron 29, 99-113. doi: 10.1016/S0896-6273(01)00183-0

Poitry-Yamate, C. L., Poitry, S., and Tsacopoulos, M. (1995). Lactate released by Müller glial cells is metabolized by photoreceptors from mammalian retina. J. Neurosci. 15, 5179-5191. doi: 10.1523/jneurosci.15-07-05179.1995

Poitry-Yamate, C. L., and Tsacopoulos, M. (1992). Glucose metabolism in freshly isolated Müller glial cells from a mammalian retina. J. Comp. Neurol 320, 257-266. doi: 10.1002/cne.903200209

Polazzi, E., Gianni, T., and Contestabile, A. (2001). Microglial cells protect cerebellar granule neurons from apoptosis: evidence for reciprocal signaling. Glia 36, 271-280. doi: 10.1002/glia.1115

Pont-Lezica, L., Beumer, W., Colasse, S., Drexhage, H., Versnel, M., and Bessis, A. (2014). Microglia shape corpus callosum axon tract fasciculation: functional impact of prenatal inflammation. Eur. J. Neurosci. 39, 1551-1557. doi: 10.1111/ ejn. 12508

Pooya, S., Liu, X., Kumar, V. B. S., Anderson, J., Imai, F., Zhang, W., et al. (2014). The tumour suppressor LKB1 regulates myelination through mitochondrial metabolism. Nat. Commun. 5:4993. doi: 10.1038/ncomms5993

Porter, J. T., and McCarthy, K. D. (1996). Hippocampal astrocytes in situ respond to glutamate released from synaptic terminals. J. Neurosci. 16, 5073-5081. doi: 10.1523/JNEUROSCI.16-16-05073.1996

Pramatarova, A., Laganière, J., Roussel, J., Brisebois, K., and Rouleau, G. A. (2001). Neuron-specific expression of mutant superoxide dismutase 1 in transgenic mice does not lead to motor impairment. J. Neurosci. 21, 3369-3374. doi: 10.1523/jneurosci.21-10-03369.2001

Pramparo, T., Youn, Y. H., Yingling, J., Hirotsune, S., and Wynshaw-Boris, A. (2010). Novel embryonic neuronal migration and proliferation defects in Dcx mutant mice are exacerbated by Lis1 reduction. J. Neurosci. 30, 3002-3012. doi: 10.1523/JNEUROSCI.4851-09.2010

Prinz, M., Jung, S., and Priller, J. (2019). Microglia biology: one century of evolving concepts. Cell 179, 292-311. doi: 10.1016/j.cell.2019.08.053 
Procko, C., and Shaham, S. (2010). Assisted morphogenesis: glial control of dendrite shapes. Curr. Opin. Cell Biol. 22, 560-565. doi: 10.1016/j.ceb.2010. 07.005

Purice, M. D., Speese, S. D., and Logan, M. A. (2016). Delayed glial clearance of degenerating axons in aged Drosophila is due to reduced PI3K/Draper activity. Nat. Commun. 7:12871. doi: 10.1038/ncomms12871

Quinlan, R. A., Brenner, M., Goldman, J. E., and Messing, A. (2007). GFAP and its role in Alexander disease. Exp. Cell Res. 313, 2077-2087. doi: 10.1016/j.yexcr. 2007.04.004

Rakic, P. (1988). Specification of cerebral cortical areas. Science 241, 170-176. doi: 10.1126/science.3291116

Rangarajan, R., Gong, Q., and Gaul, U. (1999). Migration and function of glia in the developing Drosophila eye. Development 126, 3285-3292.

Raphael, A. R., Perlin, J. R., and Talbot, W. S. (2010). Schwann cells reposition a peripheral nerve to isolate it from postembryonic remodeling of its targets. Development 137, 3643-3649. doi: 10.1242/dev.057521

Rapti, G., Li, C., Shan, A., Lu, Y., and Shaham, S. (2017). Glia initiate brain assembly through noncanonical Chimaerin-Furin axon guidance in C. elegans. Nat. Neurosci. 20, 1350-1360. doi: 10.1038/nn.4630

Rasband, M. N., and Peles, E. (2015). The nodes of Ranvier: molecular assembly and maintenance. Cold Spring Harb. Perspect. Biol. 8:a020495. doi: 10.1101/ cshperspect.a020495

Rash, J. E., Vanderpool, K. G., Yasumura, T., Hickman, J., Beatty, J. T., and Nagy, J. I. (2016). Kv1 channels identified in rodent myelinated axons, linked to Cx29 in innermost myelin: support for electrically active myelin in mammalian saltatory conduction. J. Neurophysiol. 115, 1836-1859. doi: 10.1152/jn.01077. 2015

Reichert, F., Saada, A., and Rotshenker, S. (1994). Peripheral nerve injury induces Schwann cells to express two macrophage phenotypes: phagocytosis and the galactose-specific lectin MAC-2. J. Neurosci. 14, 3231-3245. doi: 10.1523/ jneurosci.14-05-03231.1994

Ribak, C. E., Tong, W. M. Y., and Brecha, N. C. (1996). GABA plasma membrane transporters, GAT-1 and GAT-3, display different distributions in the rat hippocampus. J. Comp. Neurol. 367, 595-606.

Riccomagno, M. M., and Kolodkin, A. L. (2015). Sculpting neural circuits by axon and dendrite pruning. Annu. Rev. Cell Dev. Biol. 31, 779-805. doi: 10.1146/ annurev-cellbio-100913-013038

Rigby, M. J., Gomez, T. M., and Puglielli, L. (2020). Glial cell-axonal growth cone interactions in neurodevelopment and regeneration. Front. Neurosci. 14:203. doi: $10.3389 /$ fnins.2020.00203

Robberecht, W., and Philips, T. (2013). The changing scene of amyotrophic lateral sclerosis. Nat. Rev. Neurosci. 14, 248-264. doi: 10.1038/nrn3430

Rodríguez, J. J., and Verkhratsky, A. (2011). Neurogenesis in Alzheimer's disease. J. Anat. 219, 78-89. doi: 10.1111/j.1469-7580.2011.01343.x

Rowlands, D., Lensjø, K. K., Dinh, T., Yang, S., Andrews, M. R., Hafting, T., et al. (2018). Aggrecan directs extracellular matrix-mediated neuronal plasticity. J. Neurosci. 38, 10102-10113. doi: 10.1523/JNEUROSCI.1122-18.2018

Saab, A. S., Tzvetavona, I. D., Trevisiol, A., Baltan, S., Dibaj, P., Kusch, K., et al. (2016). Oligodendroglial NMDA receptors regulate glucose import and axonal energy metabolism. Neuron 91, 119-132. doi: 10.1016/j.neuron.2016.05.016

Salcedo-Arellano, M. J., Dufour, B., McLennan, Y., Martinez-Cerdeno, V., and Hagerman, R. (2020). Fragile X syndrome and associated disorders: clinical aspects and pathology. Neurobiol. Dis. 136:104740. doi: 10.1016/j.nbd.2020. 104740

Salter, M. W., and Stevens, B. (2017). Microglia emerge as central players in brain disease. Nat. Med. 23, 1018-1027. doi: 10.1038/nm.4397

Salzer, J. L. (2015). Schwann cell myelination. Cold Spring Harb. Perspect. Biol. 7:a020529. doi: 10.1101/cshperspect.a020529

Santosa, K. B., Keane, A. M., Jablonka-Shariff, A., Vannucci, B., and SnyderWarwick, A. K. (2018). Clinical relevance of terminal Schwann cells: an overlooked component of the neuromuscular junction. J. Neurosci. Res. 96, 1125-1135. doi: 10.1002/jnr.24231

Schafer, D. P., Heller, C. T., Gunner, G., Heller, M., Gordon, C., Hammond, T., et al. (2016). Microglia contribute to circuit defects in Mecp2 null mice independent of microglia-specific loss of Mecp2 expression. eLife 5:e15224. doi: 10.7554/eLife.15224

Schafer, D. P., Lehrman, E. K., Kautzman, A. G., Koyama, R., Mardinly, A. R., Yamasaki, R., et al. (2012). Microglia sculpt postnatal neural circuits in an activity and complement-dependent manner. Neuron 74, 691-705. doi: 10 . 1016/j.neuron.2012.03.026

Scholl, U. I., Choi, M., Liu, T., Ramaekers, V. T., Häusler, M. G., Grimmer, J., et al. (2009). Seizures, sensorineural deafness, ataxia, mental retardation, and electrolyte imbalance (SeSAME syndrome) caused by mutations in KCNJ10. Proc. Natl. Acad. Sci. U.S.A. 106, 5842-5847. doi: 10.1073/pnas.0901749106

Schousboe, A., Bak, L. K., and Waagepetersen, H. S. (2013). Astrocytic control of biosynthesis and turnover of the neurotransmitters glutamate and GABA. Front. Endocrinol. 4:102. doi: 10.3389/fendo.2013.00102

Scott-Hewitt, N., Perrucci, F., Morini, R., Erreni, M., Mahoney, M., Witkowska, A., et al. (2020). Local externalization of phosphatidylserine mediates developmental synaptic pruning by microglia. EMBO J. 39:e105380. doi: 10 . 15252/embj. 2020105380

Sedel, F., Béchade, C., Vyas, S., and Triller, A. (2004). Macrophage-derived tumor necrosis factor $\alpha$, an early developmental signal for motoneuron death. J. Neurosci. 24, 2236-2246. doi: 10.1523/JNEUROSCI.4464-03.2004

Segawa, K., and Nagata, S. (2015). An apoptotic "Eat me" signal: phosphatidylserine exposure. Trends Cell Biol. 25, 639-650. doi: 10.1016/j.tcb.2015.08.003

Seifert, G., Henneberger, C., and Steinhäuser, C. (2018). Diversity of astrocyte potassium channels: an update. Brain Res. Bull. 136, 26-36. doi: 10.1016/j. brainresbull.2016.12.002

Seifert, G., Hüttmann, K., Binder, D. K., Hartmann, C., Wyczynski, A., Neusch, C., et al. (2009). Analysis of astroglial K+ channel expression in the developing hippocampus reveals a predominant role of the Kir4.1 subunit. J. Neurosci. 29, 7474-7488. doi: 10.1523/JNEUROSCI.3790-08.2009

Sekar, A., Bialas, A. R., De Rivera, H., Davis, A., Hammond, T. R., Kamitaki, N., et al. (2016). Schizophrenia risk from complex variation of complement component 4. Nature 530, 177-183. doi: 10.1038/nature16549

Sepp, K. J., Schulte, J., and Auld, V. J. (2000). Developmental dynamics of peripheral glia in Drosophila melanogaster. Glia 30, 122-133.

Sepp, K. J., Schulte, J., and Auld, V. J. (2001). Peripheral glia direct axon guidance across the CNS/PNS transition zone. Dev. Biol. 238, 47-63. doi: 10.1006/dbio. 2001.0411

Shao, Z., Watanabe, S., Christensen, R., Jorgensen, E. M., and Colón-Ramos, D. A. (2013). Synapse location during growth depends on glia location. Cell 154, 337-350. doi: 10.1016/j.cell.2013.06.028

Shi, Q., Colodner, K. J., Matousek, S. B., Merry, K., Hong, S., Kenison, J. E., et al. (2015). Complement C3-deficient mice fail to display age-related hippocampal decline. J. Neurosci. 35, 13029-13042. doi: 10.1523/JNEUROSCI.1698-15.2015

Shin, J., Berg, D. A., Zhu, Y., Shin, J. Y., Song, J., Bonaguidi, M. A., et al. (2015). Single-Cell RNA-Seq with waterfall reveals molecular cascades underlying adult neurogenesis. Cell Stem Cell 17, 360-372. doi: 10.1016/j.stem.2015.07.013

Shklover, J., Levy-Adam, F., and Kurant, E. (2015). Apoptotic cell clearance in development. Curr. Top. Dev. Biol. 114, 297-334. doi: 10.1016/bs.ctdb.2015. 07.024

Shklyar, B., Sellman, Y., Shklover, J., Mishnaevski, K., Levy-Adam, F., and Kurant, E. (2014). Developmental regulation of glial cell phagocytic function during Drosophila embryogenesis. Dev. Biol. 393, 255-269. doi: 10.1016/j.ydbio.2014. 07.005

Shu, T., Sundaresan, V., McCarthy, M. M., and Richards, L. J. (2003). Slit2 guides both precrossing and postcrossing callosal axons at the midline in vivo. J. Neurosci. 23, 8176-8184. doi: 10.1523/JNEUROSCI.23-22-08176.2003

Sieger, D., and Peri, F. (2013). Animal models for studying microglia: the first, the popular, and the new. Glia 61, 3-9. doi: 10.1002/glia.22385

Sierra, A., Encinas, J. M., Deudero, J. J. P., Chancey, J. H., Enikolopov, G., Overstreet-Wadiche, L. S., et al. (2010). Microglia shape adult hippocampal neurogenesis through apoptosis-coupled phagocytosis. Cell Stem Cell 7, 483495. doi: 10.1016/j.stem.2010.08.014

Silbereis, J. C., Pochareddy, S., Zhu, Y., Li, M., and Sestan, N. (2016). The cellular and molecular landscapes of the developing human central nervous system. Neuron 89, 248-268. doi: 10.1016/j.neuron.2015.12.008

Simons, M., and Nave, K. A. (2016). Oligodendrocytes: myelination and axonal support. Cold Spring Harb. Perspect. Biol. 8:a020479. doi: 10.1101/cshperspect. a020479

Simpson, A. H., Gillingwater, T. H., Anderson, H., Cottrell, D., Sherman, D. L., Ribchester, R. R., et al. (2013). Effect of limb lengthening on internodal length and conduction velocity of peripheral nerve. J. Neurosci. 33, 4536-4539. doi: 10.1523/JNEUROSCI.4176-12.2013 
Sims, J., Durgun, M. B., and Gilmore, S. A. (1998). Schwann cell invasion of ventral spinal cord: the effect of irradiation on astrocyte barriers. J. Neuropathol. Exp. Neurol. 57, 866-873. doi: 10.1097/00005072-199809000-00008

Singh, R., Letai, A., and Sarosiek, K. (2019). Regulation of apoptosis in health and disease: the balancing act of BCL-2 family proteins. Nat. Rev. Mol. Cell Biol. 20, 175-193. doi: 10.1038/s41580-018-0089-8

Singhvi, A., Liu, B., Friedman, C. J., Fong, J., Lu, Y., Huang, X. Y., et al. (2016). A glial $\mathrm{K} / \mathrm{Cl}$ transporter controls neuronal receptive ending shape by chloride inhibition of an rGC. Cell 165, 936-948. doi: 10.1016/j.cell.2016. 03.026

Singhvi, A., and Shaham, S. (2019). Glia-neuron interactions in Caenorhabditis elegans. Annu. Rev. Neurosci. 42, 149-168. doi: 10.1146/annurev-neuro070918-050314

Sirerol-Piquer, M. S., Belenguer, G., Morante-Redolat, J. M., Duart-Abadia, P., Perez-Villalba, A., and Fariñas, I. (2019). Physiological interactions between microglia and neural stem cells in the adult subependymal niche. Neuroscience 405, 77-91. doi: 10.1016/j.neuroscience.2019.01.009

Smith, C. J., Johnson, K., Welsh, T. G., and Barresi, M. J. F. (2016). Radial glia inhibit peripheral glial infiltration into the spinal cord at motor exit point transition zones. Glia 64, 1138-1153. doi: 10.1002/glia.22987

Smith, C. J., Morris, A. D., Welsh, T. G., and Kucenas, S. (2014). Contact-mediated inhibition between oligodendrocyte progenitor cells and motor exit point glia establishes the spinal cord transition zone. PLoS Biol. 12:e1001961. doi: 10.1371/ journal.pbio.1001961

Snaidero, N., Velte, C., Myllykoski, M., Raasakka, A., Ignatev, A., Werner, H. B., et al. (2017). Antagonistic functions of MBP and CNP establish cytosolic channels in CNS myelin. Cell Rep. 18, 314-323. doi: 10.1016/j.celrep.2016. 12.053

Sofroniew, M. V. (2018). Dissecting spinal cord regeneration perspective. Nature 557, 343-350. doi: 10.1038/s41586-018-0068-4

Sominsky, L., De Luca, S., and Spencer, S. J. (2018). Microglia: key players in neurodevelopment and neuronal plasticity. Int. J. Biochem. Cell Biol. 94, 56-60. doi: 10.1016/j.biocel.2017.11.012

Song, H., Stevens, C. F., and Gage, F. H. (2002). Astroglia induce neurogenesis from adult neural stem cells. Nature 417, 39-44. doi: 10.1038/417039a

Song, I., and Dityatev, A. (2018). Crosstalk between glia, extracellular matrix and neurons. Brain Res. Bull. 136, 101-108. doi: 10.1016/j.brainresbull.2017.03.003

Sousa-Nunes, R., Yee, L. L., and Gould, A. P. (2011). Fat cells reactivate quiescent neuroblasts via TOR and glial insulin relays in Drosophila. Nature 471, 508-513. doi: $10.1038 /$ nature09867

Spéder, P., and Brand, A. H. (2018). Systemic and local cues drive neural stem cell niche remodelling during neurogenesis in drosophila. eLife 7:e30413. doi: 10.7554/eLife.30413

Spindler, S. R., Ortiz, I., Fung, S., Takashima, S., and Hartenstein, V. (2009). Drosophila cortex and neuropile glia influence secondary axon tract growth, pathfinding, and fasciculation in the developing larval brain. Dev. Biol. 334, 355-368. doi: 10.1016/j.ydbio.2009.07.035

Squarzoni, P., Oller, G., Hoeffel, G., Pont-Lezica, L., Rostaing, P., Low, D., et al. (2014). Microglia modulate wiring of the embryonic forebrain. Cell Rep. 8, 1271-1279. doi: 10.1016/j.celrep.2014.07.042

Squarzoni, P., Thion, M. S., and Garel, S. (2015). Neuronal and microglial regulators of cortical wiring: usual and novel guideposts. Front. Neurosci. 9:248. doi: $10.3389 /$ fnins.2015.00248

Srinivasan, R., Huang, B. S., Venugopal, S., Johnston, A. D., Chai, H., Zeng, H., et al. (2015). $\mathrm{Ca}(2+)$ signaling in astrocytes from Ip3r2(-/-) mice in brain slices and during startle responses in vivo. Nat. Neurosci. 18, 708-717. doi: $10.1038 / \mathrm{nn} .4001$

Sriram, K., and Insel, P. A. (2018). G protein-coupled receptors as targets for approved drugs: How many targets and how many drugs? Mol. Pharmacol. 93, 251-258. doi: 10.1124/mol.117.111062

Stacey, S. M., Muraro, N. I., Peco, E., Labbe, A., Thomas, G. B., Baines, R. A., et al. (2010). Drosophila glial glutamate transporter Eaat1 is regulated by fringemediated notch signaling and is essential for larval locomotion. J. Neurosci. 30, 14446-14457. doi: 10.1523/JNEUROSCI.1021-10.2010

Steen, E., Terry, B. M., Rivera, E. J., Cannon, J. L., Neely, T. R., Tavares, R., et al. (2005). Impaired insulin and insulin-like growth factor expression and signaling mechanisms in Alzheimer's disease - Is this type 3 diabetes? J. Alzheimers Dis. 7, 63-80. doi: 10.3233/JAD-2005-7107
Steinman, M. Q., Gao, V., and Alberini, C. M. (2016). The role of lactate-mediated metabolic coupling between astrocytes and neurons in long-term memory formation. Front. Integr. Neurosci. 10:10. doi: 10.3389/fnint.2016.00010

Stevens, B., Allen, N. J., Vazquez, L. E., Howell, G. R., Christopherson, K. S., Nouri, N., et al. (2007). The classical complement cascade mediates CNS synapse elimination. Cell 131, 1164-1178. doi: 10.1016/j.cell.2007.10.036

Stork, T., Thomas, S., Rodrigues, F., Silies, M., Naffin, E., Wenderdel, S., et al. (2009). Drosophila neurexin IV stabilizes neuron-glia interactions at the CNS midline by binding to wrapper. Development 136, 1251-1261. doi: 10.1242/dev. 032847

Suter, T. A. C. S., and Jaworski, A. (2019). Cell migration and axon guidance at the border between central and peripheral nervous system. Science 365:eaaw8231. doi: 10.1126/science.aaw8231

Svichar, N., and Chesler, M. (2003). Surface carbonic anhydrase activity on astrocytes and neurons facilitates lactate transport. Glia 41, 415-419. doi: 10. 1002/glia.10187

Swire, M., Kotelevtsev, Y., Webb, D. J., Lyons, D. A., and Ffrench-Constant, C. (2019). Endothelin signalling mediates experience-dependent myelination in the CNS. eLife 8:e49493. doi: 10.7554/eLife. 49493

Takesian, A. E., and Hensch, T. K. (2013). Balancing plasticity/stability across brain development. Prog. Brain Res. 207, 3-34. doi: 10.1016/B978-0-444-63327-9. 00001-1

Tasdemir-Yilmaz, O. E., and Freeman, M. R. (2014). Astrocytes engage unique molecular programs to engulf pruned neuronal debris from distinct subsets of neurons. Genes Dev. 28, 20-33. doi: 10.1101/gad.229518.113

Than-Trong, E., and Bally-Cuif, L. (2015). Radial glia and neural progenitors in the adult zebrafish central nervous system. Glia 63, 1406-1428. doi: 10.1002/glia. 22856

Thion, M. S., and Garel, S. (2017). On place and time: microglia in embryonic and perinatal brain development. Curr. Opin. Neurobiol. 47, 121-130. doi: 10.1016/j.conb.2017.10.004

Tomassy, G. S., Berger, D. R., Chen, H. H., Kasthuri, N., Hayworth, K. J., Vercelli, A., et al. (2014). Distinct profiles of myelin distribution along single axons of pyramidal neurons in the neocortex. Science 344, 319-324. doi: 10.1126/science. 1249766

Tong, X., Ao, Y., Faas, G. C., Nwaobi, S. E., Xu, J., Haustein, M. D., et al. (2014). Astrocyte Kir4.1 ion channel deficits contribute to neuronal dysfunction in Huntington's disease model mice. Nat. Neurosci. 17, 694-703. doi: 10.1038/nn. 3691

Trommsdorff, M., Gotthardt, M., Hiesberger, T., Shelton, J., Stockinger, W., Nimpf, J., et al. (1999). Reeler/disabled-like disruption of neuronal migration in knockout mice lacking the VLDL receptor and ApoE receptor 2. Cell 97, 689-701. doi: 10.1016/S0092-8674(00)80782-5

Tsacopoulos, M., Coles, J. A., and Van de Werve, G. (1987). The supply of metabolic substrate from glia to photoreceptors in the retina of the honeybee drone. J. Physiol. 82, 279-287.

Tsacopoulos, M., Evêquoz-Mercier, V., Perrottet, P., and Buchner, E. (1988). Honeybee retinal glial cells transform glucose and supply the neurons with metabolic substrate. Proc. Natl. Acad. Sci. U.S.A. 85, 8727-8731. doi: 10.1073/ pnas.85.22.8727

Tsacopoulos, M., and Poitry, S. (1982). Kinetics of oxygen consumption after a single flash of light in photoreceptors of the drone (Apis mellifera). J. Gen. Physiol. 80, 19-55. doi: 10.1085/jgp.80.1.19

Ueno, M., Fujita, Y., Tanaka, T., Nakamura, Y., Kikuta, J., Ishii, M., et al. (2013). Layer $\mathrm{v}$ cortical neurons require microglial support for survival during postnatal development. Nat. Neurosci. 16, 543-551. doi: 10.1038/nn.3358

Ueno, M., and Yamashita, T. (2014). Bidirectional tuning of microglia in the developing brain: from neurogenesis to neural circuit formation. Curr. Opin. Neurobiol. 27, 8-15. doi: 10.1016/j.conb.2014.02.004

Ullian, E. M., Sapperstein, S. K., Christopherson, K. S., and Barres, B. A. (2001). Control of synapse number by glia. Science 291, 657-661. doi: 10.1126/science. 291.5504.657

Vainchtein, I. D., Chin, G., Cho, F. S., Kelley, K. W., Miller, J. G., Chien, E. C., et al. (2018). Astrocyte-derived interleukin-33 promotes microglial synapse engulfment and neural circuit development. Science 359, 1269-1273. doi: 10. 1126/science.aal3589

Van Damme, P., Van Den Bosch, L., Van Houtte, E., Callewaert, G., and Robberecht, W. (2002). GluR2-dependent properties of AMPA receptors 
determine the selective vulnerability of motor neurons to excitotoxicity. J. Neurophysiol. 88, 1279-1287. doi: 10.1152/jn.2002.88.3.1279

van der Zee, E. A., de Jong, G. I., Strosberg, A. D., and Luiten, P. G. M. (1993). Muscarinic acetylcholine receptor-expression in astrocytes in the cortex of young and aged rats. Glia 8, 42-50. doi: 10.1002/glia.440080106

Vasek, M. J., Garber, C., Dorsey, D., Durrant, D. M., Bollman, B., Soung, A., et al. (2016). A complement-microglial axis drives synapse loss during virus-induced memory impairment. Nature 534, 538-543. doi: 10.1038/nature18283

Vecino, E., Hernández, M., and García, M. (2004). Cell death in the developing vertebrate retina. Int. J. Dev. Biol. 48, 965-974. doi: 10.1387/ijdb.041891ev

Verkhratsky, A., Ho, M. S., and Parpura, V. (2019). Evolution of Neuroglia. Adv. Exp. Med. Biol. 1175, 15-44. doi: 10.1007/978-981-13-9913-8_2

Vermeren, M., Maro, G. S., Bron, R., McGonnell, I. M., Charnay, P., Topilko, P., et al. (2003). Integrity of developing spinal motor columns is regulated by neural crest derivatives at motor exit points. Neuron 37, 403-415. doi: 10.1016/S08966273(02)01188-1

Vicidomini, C., Guo, N., and Sahay, A. (2020). Communication, cross talk, and signal integration in the adult hippocampal neurogenic niche. Neuron 105, 220-235. doi: 10.1016/j.neuron.2019.11.029

Volkenhoff, A., Weiler, A., Letzel, M., Stehling, M., Klämbt, C., and Schirmeier, S. (2015). Glial glycolysis is essential for neuronal survival in Drosophila. Cell Metab. 22, 437-447. doi: 10.1016/j.cmet.2015.07.006

Wakselman, S., Béchade, C., Roumier, A., Bernard, D., Triller, A., and Bessis, A. (2008). Developmental neuronal death in hippocampus requires the microglial CD11b integrin and DAP12 immunoreceptor. J. Neurosci. 28, 8138-8143. doi: 10.1523/JNEUROSCI.1006-08.2008

Wallace, S. W., Singhvi, A., Liang, Y., Lu, Y., and Shaham, S. (2016). PROS$1 /$ Prospero is a major regulator of the glia-specific secretome controlling sensory-neuron shape and function in C. elegans. Cell Rep. 15, 550-562. doi: 10.1016/j.celrep.2016.03.051

Walton, N. M., Sutter, B. M., Laywell, E. D., Levkoff, L. H., Kearns, S. M., Marshall, G. P. II, et al. (2006). Microglia instruct subventricular zone neurogenesis. Glia 54, 815-825. doi: 10.1002/glia.20419

Wandall, H. H., Pizette, S., Pedersen, J. W., Eichert, H., Levery, S. B., Mandel, U., et al. (2005). Egghead and brainiac are essential for glycosphingolipid biosynthesis in vivo. J. Biol. Chem. 280, 4858-4863. doi: 10.1074/jbc. C400571200

Wang, H. (2018). Modeling neurological diseases with human brain organoids. Front. Synaptic Neurosci. 10:15. doi: 10.3389/fnsyn.2018.00015

Wang, H., Kunkel, D. D., Martin, T. M., Schwartzkroin, P. A., and Tempel, B. L. (1993). Heteromultimeric $\mathrm{K}+$ channels in terminal and juxtaparanodal regions of neurons. Nature 365, 75-79. doi: 10.1038/365075a0

Wang, H. C., Lin, C. C., Cheung, R., Zhang-Hooks, Y., Agarwal, A., Ellis-Davies, G., et al. (2015). Spontaneous activity of cochlear hair cells triggered by fluid secretion mechanism in adjacent support cells. Cell 163, 1348-1359. doi: 10. 1016/j.cell.2015.10.070

Wang, L., Gutmann, D. H., and Roos, R. P. (2011). Astrocyte loss of mutant SOD1 delays ALS disease onset and progression in G85R transgenic mice. Hum. Mol. Genet. 20, 286-293. doi: 10.1093/hmg/ddq463

Wang, L., Hagemann, T. L., Kalwa, H., Michel, T., Messing, A., and Feany, M. B. (2015). Nitric oxide mediates glial-induced neurodegeneration in Alexander disease. Nat. Commun. 6:8966. doi: 10.1038/ncomms9966

Warden, M. R., Selimbeyoglu, A., Mirzabekov, J. J., Lo, M., Thompson, K. R., Kim, S. Y., et al. (2012). A prefrontal cortex-brainstem neuronal projection that controls response to behavioural challenge. Nature 492, 428-432. doi: 10.1038/ nature 11617

Werneburg, S., Feinberg, P. A., Johnson, K. M., and Schafer, D. P. (2017). A microglia-cytokine axis to modulate synaptic connectivity and function. Curr. Opin. Neurobiol. 47, 138-145. doi: 10.1016/j.conb.2017.10.002

Werneburg, S., Jung, J., Kunjamma, R. B., Ha, S. K., Luciano, N. J., Willis, C. M., et al. (2020). Targeted complement inhibition at synapses prevents microglial synaptic engulfment and synapse loss in demyelinating disease. Immunity 52, 167-182.e7. doi: 10.1016/j.immuni.2019.12.004

Wilcock, D. M., Vitek, M. P., and Colton, C. A. (2009). Vascular amyloid alters astrocytic water and potassium channels in mouse models and humans with Alzheimer's disease. Neuroscience 159, 1055-1069. doi: 10.1016/j.neuroscience. 2009.01.023
Wilton, D. K., Dissing-Olesen, L., and Stevens, B. (2019). Neuron-Glia signaling in synapse elimination. Annu. Rev. Neurosci. 42, 107-127. doi: 10.1146/annurevneuro-070918-050306

Wray, S. (2010). From nose to brain: development of gonadotrophin-releasing hormone -1 neurones. J. Neuroendocrinol. 22, 743-753. doi: 10.1111/j.13652826.2010.02034.x

Wu, B., Li, J., Chou, Y. H., Luginbuhl, D., and Luo, L. (2017). Fibroblast growth factor signaling instructs ensheathing glia wrapping of Drosophila olfactory glomeruli. Proc. Natl. Acad. Sci. U.S.A. 114, 7505-7512. doi: 10.1073/pnas. 1706533114

Wu, H. H., Bellmunt, E., Scheib, J. L., Venegas, V., Burkert, C., Reichardt, L. F., et al. (2009). Glial precursors clear sensory neuron corpses during development via Jedi-1, an engulfment receptor. Nat. Neurosci. 12, 1534-1541. doi: 10.1038/ nn.2446

Wu, Y., Dissing-Olesen, L., MacVicar, B. A., and Stevens, B. (2015). Microglia: dynamic mediators of synapse development and plasticity. Trends Immunol. 36, 605-613. doi: 10.1016/j.it.2015.08.008

Wynshaw-Boris, A., Pramparo, T., Youn, Y. H., and Hirotsune, S. (2010). Lissencephaly: mechanistic insights from animal models and potential therapeutic strategies. Semin. Cell Dev. Biol. 21, 823-830. doi: 10.1016/j.semcdb. 2010.07.008

Xin, W., Mironova, Y. A., Shen, H., Marino, R. A. M., Waisman, A., Lamers, W. H., et al. (2019). Oligodendrocytes support neuronal glutamatergic transmission via expression of glutamine synthetase. Cell Rep. 27, 2262-2271.e5. doi: 10.1016/ j.celrep.2019.04.094

Yamaguchi, Y., and Miura, M. (2015). Programmed cell death in neurodevelopment. Dev. Cell 32, 478-490. doi: 10.1016/j.devcel.2015.01.019

Yamanaka, K., and Komine, O. (2018). The multi-dimensional roles of astrocytes in ALS. Neurosci. Res. 126, 31-38. doi: 10.1016/j.neures.2017.09.011

Yan, Y. P., Sailor, K. A., Vemuganti, R., and Dempsey, R. J. (2006). Insulin-like growth factor-1 is an endogenous mediator of focal ischemia-induced neural progenitor proliferation. Eur. J. Neurosci. 24, 45-54. doi: 10.1111/j.1460-9568. 2006.04872.x

Yang, G., Pan, F., and Gan, W.-B. (2009). Stably maintained dendritic spines are associated with lifelong memories. Nature 462, 920-924. doi: 10.1038/ nature 08577

Yasugi, T., Sugie, A., Umetsu, D., and Tabata, T. (2010). Coordinated sequential action of EGFR and Notch signaling pathways regulates proneural wave progression in the Drosophila optic lobe. Development 137, 3193-3203. doi: 10.1242/dev.048058

Yeh, F. L., Wang, Y., Tom, I., Gonzalez, L. C., and Sheng, M. (2016). TREM2 binds to apolipoproteins, including APOE and CLU/APOJ, and thereby facilitates uptake of amyloid-beta by microglia. Neuron 91, 328-340. doi: 10.1016/j. neuron.2016.06.015

Yildirim, K., Petri, J., Kottmeier, R., and Klämbt, C. (2019). Drosophila glia: few cell types and many conserved functions. Glia 67, 5-26. doi: 10.1002/glia.23459

Yoshida, A., Nakano, S., Suzuki, T., Ihara, K., Higashiyama, T., and Mori, I. (2016). A glial K+/Cl- cotransporter modifies temperature-evoked dynamics in Caenorhabditis elegans sensory neurons. Genes Brain Behav. 15, 429-440. doi: $10.1111 / \mathrm{gbb} .12260$

Yoshimura, S., Murray, J. I., Lu, Y., Waterston, R. H., and Shaham, S. (2008). mls-2 and vab-3 control glia development, h/h-17/Olig expression and gliadependent neurite extension in C. elegans. Development 135, 2263-2275. doi: 10.1242/dev.019547

Yuan, X., Sipe, C. W., Suzawa, M., Bland, M. L., and Siegrist, S. E. (2020). Dilp-2-mediated PI3-kinase activation coordinates reactivation of quiescent neuroblasts with growth of their glial stem cell niche. PLoS Biol. 18:e3000721. doi: 10.1371/journal.pbio.3000721

Zakerp, Z., Penaloza, C. G., Smith, K., Ye, Y., and Lockshin, R. A. (2015). What cell death does in development. Int. J. Dev. Biol. 59, 11-22. doi: 10.1387/ijdb. $150220 \mathrm{zz}$

Zhang, R. W., Du, W. J., Prober, D. A., and Du, J. L. (2019). Müller glial cells participate in retinal waves via glutamate transporters and AMPA receptors. Cell Rep. 27, 2871-2880.e2. doi: 10.1016/j.celrep.2019. 05.011

Zhang, W., Ma, L., Yang, M., Shao, Q., Xu, J., Lu, Z., et al. (2020). Cerebral organoid and mouse models reveal a RAB39b-PI3K-mTOR pathway-dependent 
dysregulation of cortical development leading to macrocephaly/autism phenotypes. Genes Dev. 34, 580-597. doi: 10.1101/gad.332494.119

Zhang, Y., Chen, K., Sloan, S. A., Bennett, M. L., Scholze, A. R., O'Keeffe, S., et al. (2014). An RNA-sequencing transcriptome and splicing database of glia, neurons, and vascular cells of the cerebral cortex. J. Neurosci. 34, 11929-11947. doi: 10.1523/JNEUROSCI.186014.2014

Zhou, Z., Hartwieg, E., and Horvitz, H. R. (2001). CED-1 is a transmembrane receptor that mediates cell corpse engulfment in C. elegans. Cell 104, 43-56. doi: 10.1016/S0092-8674(01)00190-8
Conflict of Interest: The authors declare that the research was conducted in the absence of any commercial or financial relationships that could be construed as a potential conflict of interest.

Copyright $\odot 2020$ Lago-Baldaia, Fernandes and Ackerman. This is an open-access article distributed under the terms of the Creative Commons Attribution License (CC BY). The use, distribution or reproduction in other forums is permitted, provided the original author(s) and the copyright owner(s) are credited and that the original publication in this journal is cited, in accordance with accepted academic practice. No use, distribution or reproduction is permitted which does not comply with these terms. 


\section{GLOSSARY}

Apoptosis: The most common form of programmed cell death, essential in development and tissue homeostasis. This mechanism is energy-dependent, and when triggered, results in the activation of cysteine proteases (caspases) that degrade cellular components.

Blood brain barrier (BBB): A protective membrane structure generated by a combination of epithelial cells and glial processes that separates the nervous system from blood circulation. The BBB protects the nervous system from toxins and pathogens and maintains its homeostasis and function by regulating the passage of ions, moleculas and cells.

Macroglia: Nervous system cells, excluding neurons and microglia; i.e. glia cells from non-neuronal lineages of neuroectodermic origin, including astrocytes, oligodendrocytes, Schwann cells and satellite glia.

Marginal zone: The most superficial layer (layer I) of the mammalian cortex, positioned above the cortical plate (layers II-VI). It is composed of Cajal-Retzius cells, which migrate tangentially into the neocortex and regulate radial migration of layers II-IV cortical neurons.

Neural stem cell (NSC)/Neuroblast: NSCs or Neuroblasts (invertebrate nomenclature) are the primordial multipotent cells that originate all cells, neuronal and glial, of the nervous system. In vertebrate embryogenesis, these are called radial glial cells (CNS only), which asymmetrically divide to give rise to neurons and glia.

Neural stem cell niche: Delimitated region in the developing and adult nervous system that harbors NSCs and regulates neurogenesis, also referred to as the "neurogenic niche".

Neuroblast quiescence: The reversible state of cell cycle arrest in NSCs/neuroblasts, i.e. exit of the cell cycle and entry in G0 phase, retaining capacity to re-enter cell cycle and proliferate upon reactivation (see Neuroblast reactivation).

Neuroblast reactivation: The activation of NSCs/neuroblast to re-enter the cell cycle and return to a proliferative state, regulated by intrinsic and extrinsic cues.

Neuroepithelium: Sheet of the earliest neural progenitor cells, which are of ectodermic origin, with features of a polarized epithelium connected by tight and adherens junctions. Neuroepithelial cells proliferate symmetrically and differentiate into NSCs (radial glia), in vertebrates, and neuroblasts in Drosophila.

Neuronal plasticity: The capacity of a neuron to modify the strength or structure of existing synaptic connections (synaptic plasticity) or create new synaptic connections. These anatomical and functional changes are essential for the correct development of neuronal circuits in response to experience or injury.

Neuropil: Areas of the nervous system mainly composed of unmyelinated axons, dendrites, and glia processes, mostly devoid of cell bodies and with a high density of synapses.

Outer proliferation center (OPC): One of the two optic placodes (neuroepithelial structure) formed at the end of embryogenesis, which give rise to the neurons of the four neuropils of the Drosophila optic lobe (lamina, medulla, lobula and lobula plate).

Perineuronal nets: Chondroitin sulfate proteoglycan-rich extracellular matrix structures ensheathing neuronal cell bodies and dendrites, with roles in the regulation and stabilization of synapses.

Programmed cell death (PCD): Genetically determined cell death resulting from activation of intracellular pathways. PCD mechanisms include apoptosis, autophagy, and regulated necrosis (necroptosis), each with specific/distinctive molecular and morphological features.

Radial migration: Migratory movement of neurons along radial glial fibers in the vertebrate neocortex from the most inner/ventral layer - ventricular zone - to the most dorsal/superficial cortical layer, just below the marginal zone.

Tangential migration: Migratory movement of neurons in the vertebrate neocortex perpendicular to radial migration, i.e. parallel to the marginal zone, of incoming neurons born in the ganglionic eminences.

Transition zones: Regions of the nervous system at CNS-PNS boundaries. Selective crossing of neurons, glial cells, and axons is mediated by resident pools of glia at the border.

Trophic factors: Proteins and small peptides that regulate the growth and survival of cells. Neurotrophic factors refer particularly to those regulating development, function and survival of neurons.

Ventricular zone: The most ventral/inner layer of the mammalian cortex, where the radial glial cell bodies are positioned and cortical neurons are born (proliferative zone). 